NASATM- $79-207517$

From: Afmegrom

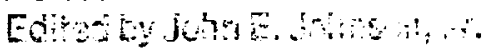

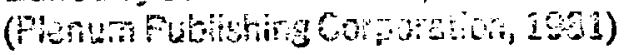

$N O$

$$
7 n-51-\pi M
$$

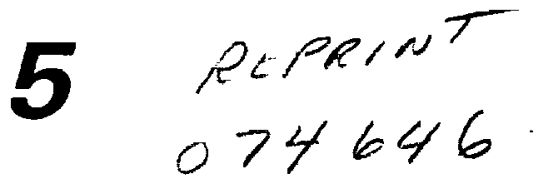

\title{
Variation
}

\section{Principles and Applications in the Study of Cell Structure and Aging}

\section{ANGELOS C. ECONOMOS, JAIME MIQUEL, RALPH C. BALLARD, and JOHN E. JOHNSON, Jr.}

\begin{abstract}
Variability is a deeply ingrained characteristic of nature and man's appreciation of variability is the source of knowledge, beauty and tolerance.
\end{abstract}

Kubis (1966)

\section{ORIGIN OF VARIATION}

In the search for general trends and laws in Nature, there is a tendency to exorcise variation as an artifact, for which imperfection and inaccuracy of observation are held responsible. However, there is of ten a residual variation and unpredictability when measurement error and external uncontrollable disturbance (noise) have been effectively removed. The following principle can be stated:

Variation is an inherent characteristic of objects and systems-be they cells or organisms, cities or countries, rocks or mountains, electric bulbs or airplanes - a consequence of the statistical (macroscopically apparently nondeterministic) nature of the processes by which the objects and systems are formed (or manufactured) from simpler elements.

Thus, physiological equality among individuals is an impossibility in sexually reproducing organisms. Individuals are "manufactured" based on an elaborate but basically random "shuffling and reshuffling of the genetic cards" (the genetic infor-

ANGELOS C. ECONOMOS and RALPH C. BALLARD - Department of Biological Sciences, San Jose State University, San Jose, California 95192. Dr. Economos's present address is: Laboratoire de Génétique, Université Catholique de Louvain, Louvain-la-Neuve, Belgium. JAIME MIQUEL - Biomedical Research Division, NASA, Ames Research Center, Moffett Field, California 94035. JOHN E. JOHN. SON. Jr. - National Institute on Aging. Section on Experimental Morphology, Baltimore City Hospitals, Baltimore, Maryland 21224; Department of Neurology. Johns Hopkins University School of Medicine, Baltimore, Maryland 21205; and Hitachi Scientific Instruments, Rockville, Maryland 20850. 
mation in the gametes) drawn from the available "genetic pool" of a population (Dawkins, 1976). This is the genotypic variation. In highly inbred populations of experimental animals, though the genetic design has become relatively fixed, implementation of the blueprint in the actual manufacturing of such a highly complex object as an individual does not produce identical copies of the prototype. Although variations introduced at the various component steps of the manufacturing process may be small, they culminate in observable differences among individuals. This is the phenotypic variation.

\section{ANALYSIS OF VARIATION}

Statistical methodology was originally developed to handle measurement error per se. Some of the assumptions, however, pertain only to measurement error and not in general to the residual variation. In handling another part of variation, i.e., noise, information theory and communication engineering have been very successful-witness, for instance, the transmission of information amidst unimaginable levels of noise (compared to signal magnitude) in planetary explorations. Finally, intensive study of variation in technological objects over the past few decades has culminated in the development of a new branch of engineering, reliability engineering (Bazovsky, 1961; Haviland, 1964; von Alven, 1964; Shooman, 1968; Brook, 1972; Carter, 1972; Jardine, 1973; Bompas-Smith, 1973; Gross and Clark, 1975; Kapur and Lamberson, 1977). The aim in this discipline is to develop an effective methodology for designing reliable machines and other technological objects or systems in spite of variations in characteristics and durability of available components. Although in biological and aging research we are not expected to design our object of study, use of concepts from reliability engineering can be useful.

Variation in a set of objects or individuals is described quantitatively by the frequency distribution, i.e., the mathematical function giving the percentage of the population with a certain value of a measured attribute within the range the attribute varies over the given group (see Fig. 1 for examples). With the passage of time, wearing-out or aging may shift and/or change the "form" of this function.

Well known is the normal or bell-shaped distribution. Its widespread occurrence stems from an interesting property of distributions, described by the "central limit theorem" (Papoulis, 1965):
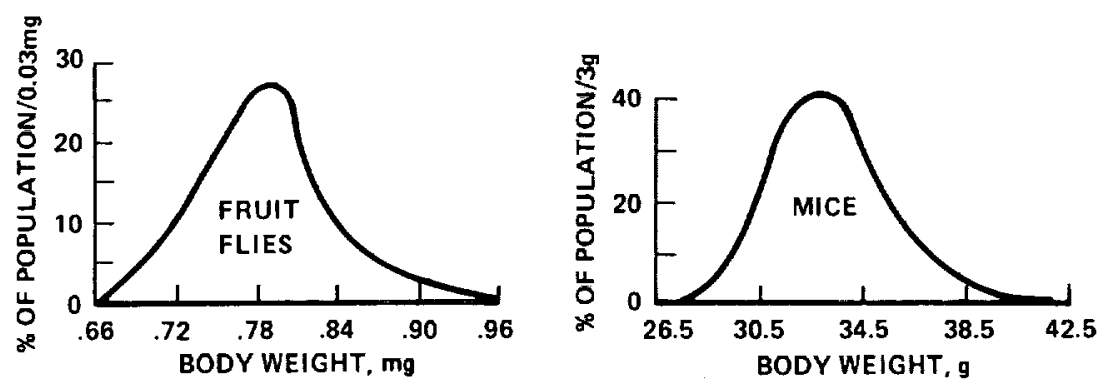

Figure 1. Frequency distribution of body weights in two inbred populations of young adult animals from this laboratory: 235 male fruit fies ( 32 days old) raised and kept at $21^{\circ} \mathrm{C}$ and 125 male $\mathrm{C} 57 \mathrm{BL} / 6 \mathrm{~J}$ mice (8 months old) kept at $24^{\circ} \mathrm{C}$. 
organism above a body temperature of roughly $40^{\circ} \mathrm{C}$ due to fast increase with temperature of the rate of thermal denaturation of protein; higher body temperature, on the other hand, increases the thermodynamic efficiency of the body's biochemical reactions. There are also other thermodynamic (e.g., heat transfer), ecological, and evolutionary constraints which are in general different in mammals and birds; this may account for the differences in the frequency distributions of Fig. 2.

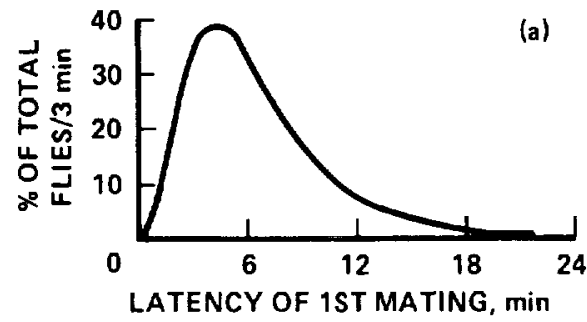

(c)
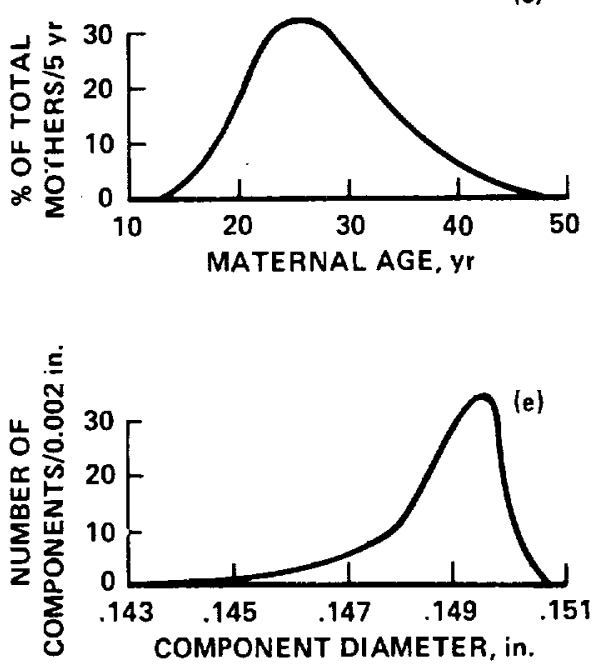

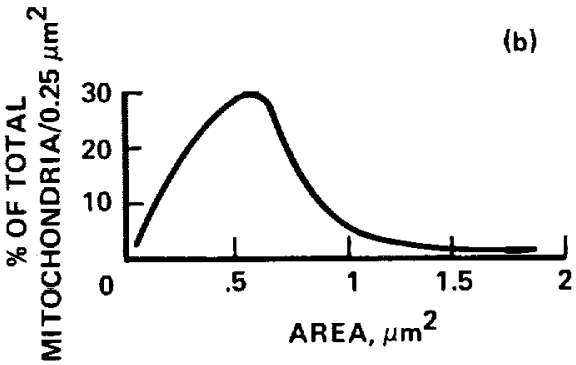

(d)
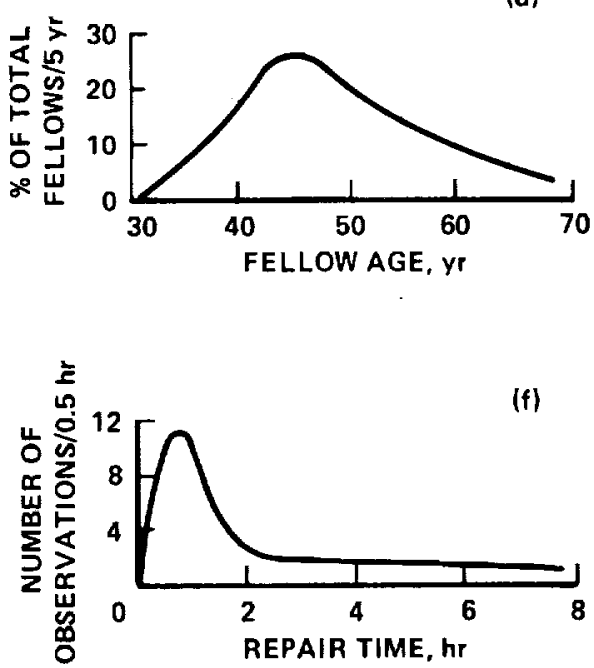

Figure 3. Typical examples of asymmetric, log-normal type distributions, of biological and technological characteristics, in which an "optimality mechanism" may be operative (see text). (a) Latency of first mating in a population of twenty-eight 4-week-old male fruit flies housed individually in vials, measured from the moment three 7-day-old virgin females were placed in each male's vial. Data from Economos et al. (1979a), Tables I and II. (b) Area of mitochondria on electron micrographs of cross sections of fibers of the flight muscle of 8-day-old houseflies. From Sohal and Bridges (1977), smoothed histogram from Fig. 5. (c) Age of mothers in a group that gave birth to 2191 children. Data from Murphy (1954) cited in Calloway and Dollevoet (1977), Table 15. (d) Age of Fellows of the Royal Society of London at election. Data from Bartlett (1970), Table 2. (e) Diameter of components turned on a hand-operated lathe to a specification of $0.150 \pm 0.001$ in., subsequently polished until a specified surface finish was achieved. From Brook (1972), smoothed histogram from Fig. 11.1. (f) Repair time of a typical (unspecified) piece of equipment. From von Alven (1964), smoothed histogram from Fig. 5.10. 


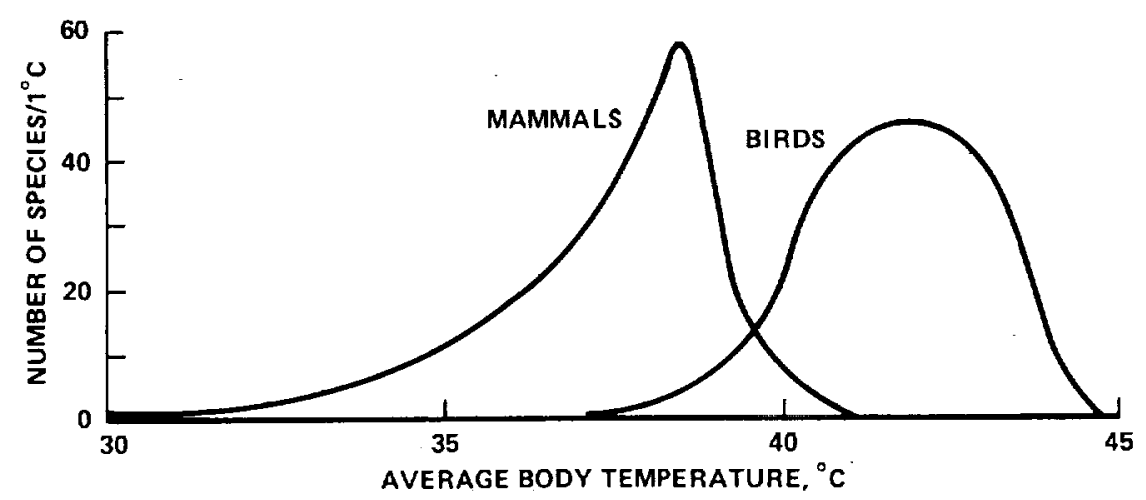

Figure 2. Frequency distribution of average body temperature in mammals and birds. From Morowitz (1968), smoothed histogram from Fig. 5.4.

If a characteristic is influenced by a large number of mutually independent factors acting additively, no matter what the form of the frequency distribution of these factors is, the composite characteristic has a bell-shaped distribution.

Factors often interact, however, or influence a characteristic in nonadditive ways. For instance, body weight $(W)$ is proportional to the product of three body dimensions $\left(L_{1} \cdot L_{2} \cdot L_{3}\right.$ ); its distribution will not be bell shaped (Fig. 1). However, the logarithm of body weight is proportional to the sum of the logarithms of the three body dimensions:

$$
W \propto L_{1} \cdot L_{2} \cdot L_{3} \rightarrow \log W \propto \log L_{1}+\log L_{2}+\log L_{3}
$$

By the central limit theorem then, $\log W$ will be roughly normally distributed. Very often, therefore, the logarithm of a characteristic will be normally distributed; such a characteristic is said to be log-normally distributed, a term coined by Gaddum in 1945 (Oldham, 1968).

An important property of this distribution is its asymmetry: a large percentage of the individuals have a certain value of the studied characteristic, fewer and fewer of them having larger or smaller values (but not both). This suggests another mechanism by which a log-normal distribution is obtained, operative where there is competition among the individuals of a group for a common resource. Many examples of this phenomenon have been reviewed by Papageorgiou (1976): size of particles formed from grinding or breakage processes, bank deposits, size of firms (compared in terms of number of employees or annual sales), size of sentences in a text (in terms of number of words), size of farms or towns in a country, size of oil reserves, and so on.

Another general mechanism that leads to an asymmetric distribution similar to a log-normal distribution is the following. In some manufacturing processes, a given specification of a certain characteristic (often an "optimal" specification by some criterion) may be more difficult to be deviated from on one side of the optimal specification within the range of permitted values than on the other side of the optimal specification. In the examples of Fig. 2, there is the severe constraint of a high bioenergetic cost to the 
organism above a body temperature of roughly $40^{\circ} \mathrm{C}$ due to fast increase with temperature of the rate of thermal denaturation of protein; higher body temperature, on the other hand, increases the thermodynamic efficiency of the body's biochemical reactions. There are also other thermodynamic (e.g., heat transfer), ecological, and evolutionary constraints which are in general different in mammals and birds; this may account for the differences in the frequency distributions of Fig. 2.

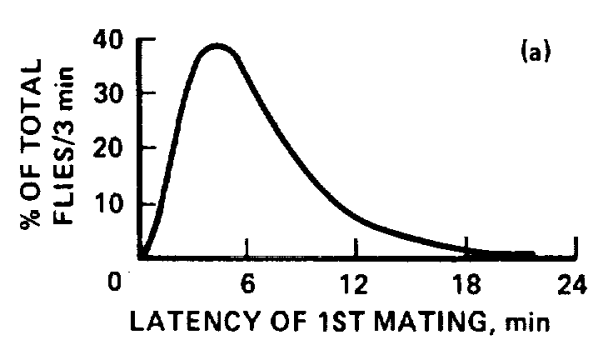

(c)
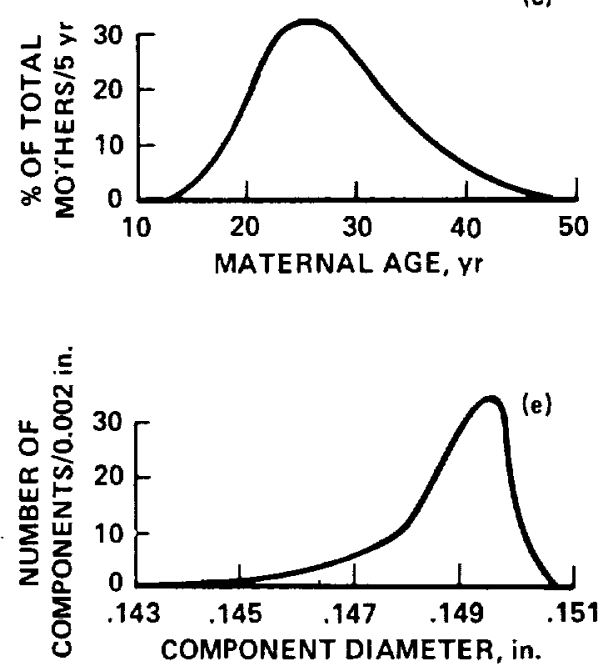

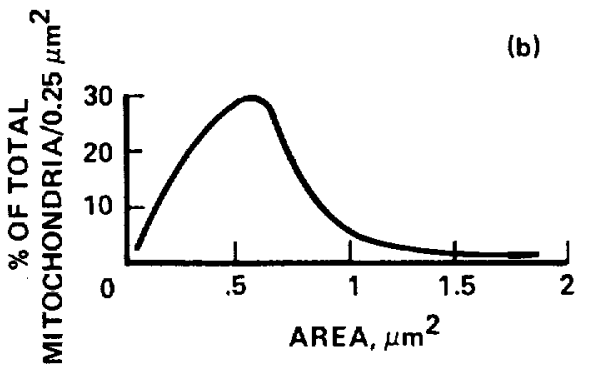

(d)
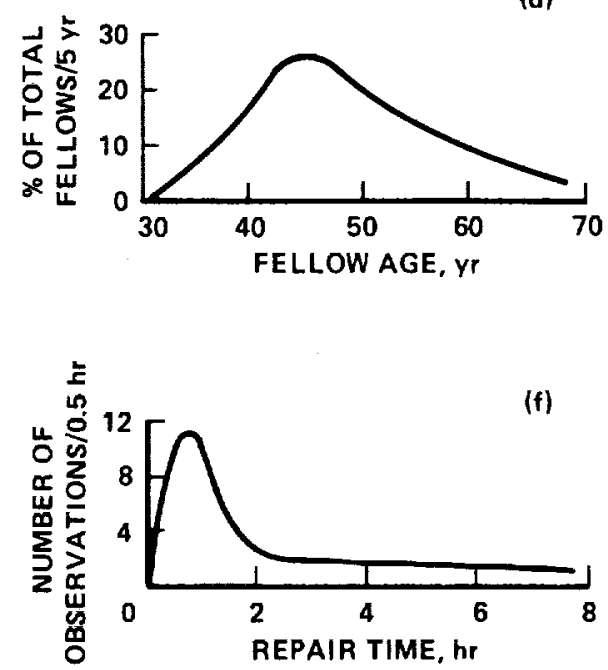

Figure 3. Typical examples of asymmetric, log-normal type distributions, of biological and technological characteristics, in which an "optimality mechanism" may be operative (see text). (a) Latency of first mating in a population of twenty-eight 4-week-old male fruit flies housed individually in vials, measured from the moment three 7-day-old virgin females were placed in each male's vial. Data from Economos et al. (1979a), Tables I and II. (b) Area of mitochondria on electron micrographs of cross sections of fibers of the flight muscle of 8-day-old houseflies. From Sohal and Bridges (1977), smoothed histogram from Fig. 5. (c) Age of mothers in a group that gave birth to 2191 children. Data from Murphy (1954) cited in Calloway and Dollevoet (1977), Table 15. (d) Age of Fellows of the Royal Society of London at election. Data from Bartlett (1970), Table 2. (e) Diameter of components turned on a hand-operated lathe to a specification of $0.150 \pm 0.001$ in., subsequently polished until a specified surface finish was achieved. From Brook (1972), smoothed histogram from Fig. II.1. (f) Repair time of a typical (unspecified) piece of equipment. From von Alven (1964), smoothed histogram from Fig. 5.10. 


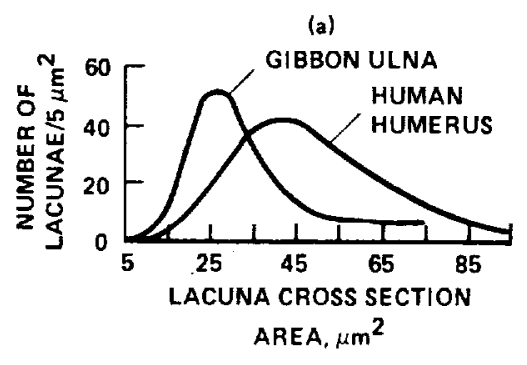

(c)

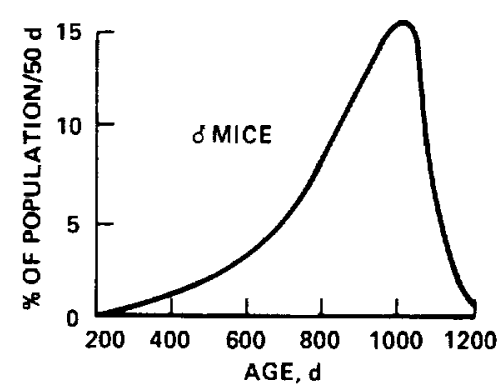

(b)

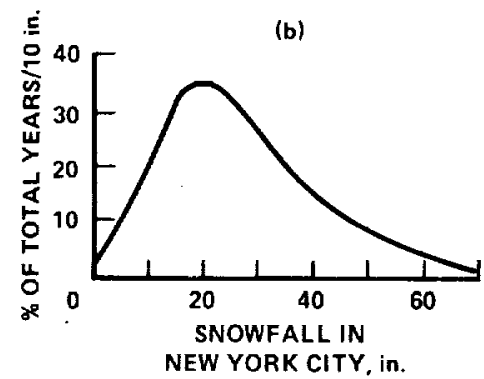

(d)

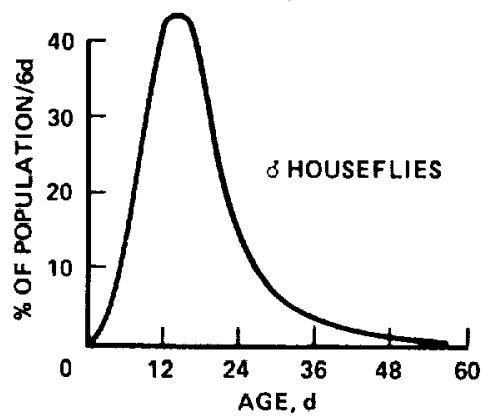

Figure 4. Examples of asymmetric log-normal type distributions whose underlying mechanism is not clear. (a) Size of lacunae in cross sections of bones. From Yeager et al. (1975), smoothed histograms from Fig. 1. (b) Snowfall in New York City in the years 1919-1953. Data from Haviland (1964), Table 10.4. (c) Frequency of deaths in a population of 296 male C57BL/6J mice. From Kunstyr and Leuenberger (1975), smoothed histogram from Fig. 4. (d) Frequency of deaths in a population of 4627 male houseflies at $25^{\circ} \mathrm{C}$ ambient temperature. Data from Rockstein and Lierberman (1959), Table III.

Further examples where the above "optimality mechanism" may be operative are shown in Fig. 3; this may be less obvious in other examples (Fig. 4), which could also be explained by other mechanisms. In some instances the asymmetry of the frequency distribution may be exaggerated to the point that no individual has a value of the studied characteristic on one side of a certain most common value. Two examples are shown in Fig. 5. As is seen by plotting the distributions on a semilogarithmic plot, each can be represented by a single exponential function.

\section{VARIATION AND AGING}

An obtrusive characteristic of organisms is that, with the passage of time, they suffer progressive deterioration of structure and function leading to senescence and death. The frequency distribution of various structural or functional characteristics of young individuals is therefore bound to change as they age. One general trend is seen 
(a)

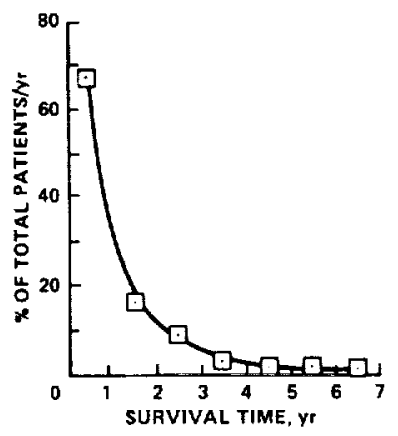

[c]

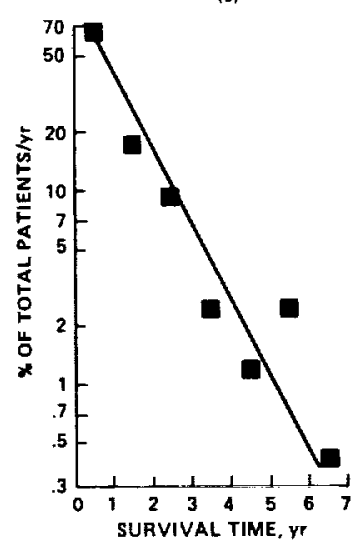

(b)
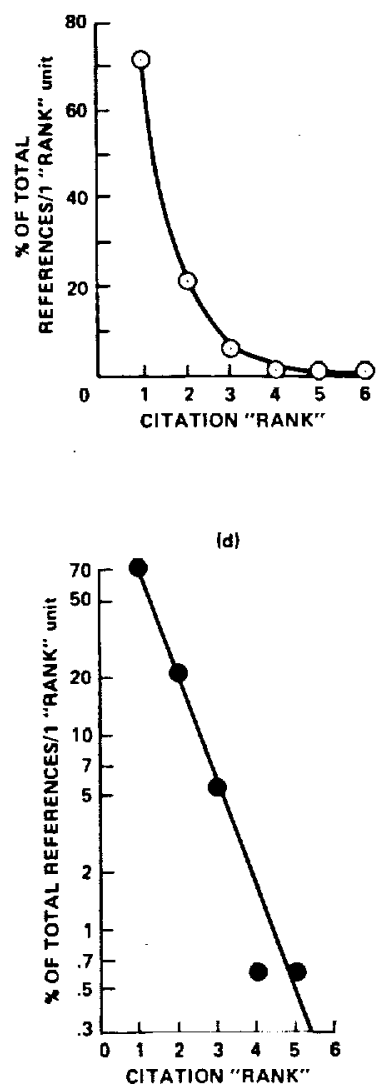

Figure 5. Examples of negative-exponential type frequency distributions. (a) Survival time of 256 patients with malignant melanoma who had metastases at the time of admission. Data from MacDonald (1963) cited in Gross and Clark (1975), Table 1.1. (b) Rank of citation of authors (number of cited papers by an author, single or first authorship only) based on 336 references from a monograph. [References appearing in a monograph by Papaikonomou (1974) were counted and tabulated.] (c) and (d) are semilogarithmic plots of (a) and (b), respectively.

in a progressive shifting of the most common (or "optimal") value of a characteristic toward less optimal levels. Another trend may be a tendency of variance to increase with age. These trends may be apparent in populations in which no appreciable mortality has yet set in. However, as progressively more weak individuals die, such trends may be less clear, because of introduced bias by elimination of the least optimal values corresponding to the individuals that have died; thus, under certain circumstances, variation may be reduced in old age. Figure 6 illustrates the observed change of the frequency distribution with age of a structural characteristic of hamsters. Two examples of aging changes in the frequency distribution of fine structural characteristics are shown in Fig. 7. A striking effect of aging is seen in Figs. 8 and 9.

A trend seen in the biological example of Fig. 6 is also evident in the technological example of Fig. 10. Here, "aging" of the capacitors could be considered to be simulated by a larger number of dielectric defects (conducting flaws). Such "aging" shifts the frequency distribution of the capacitor strength (breakdown voltage) toward lower values. Interestingly, however, the form and variance of the distribution remain 


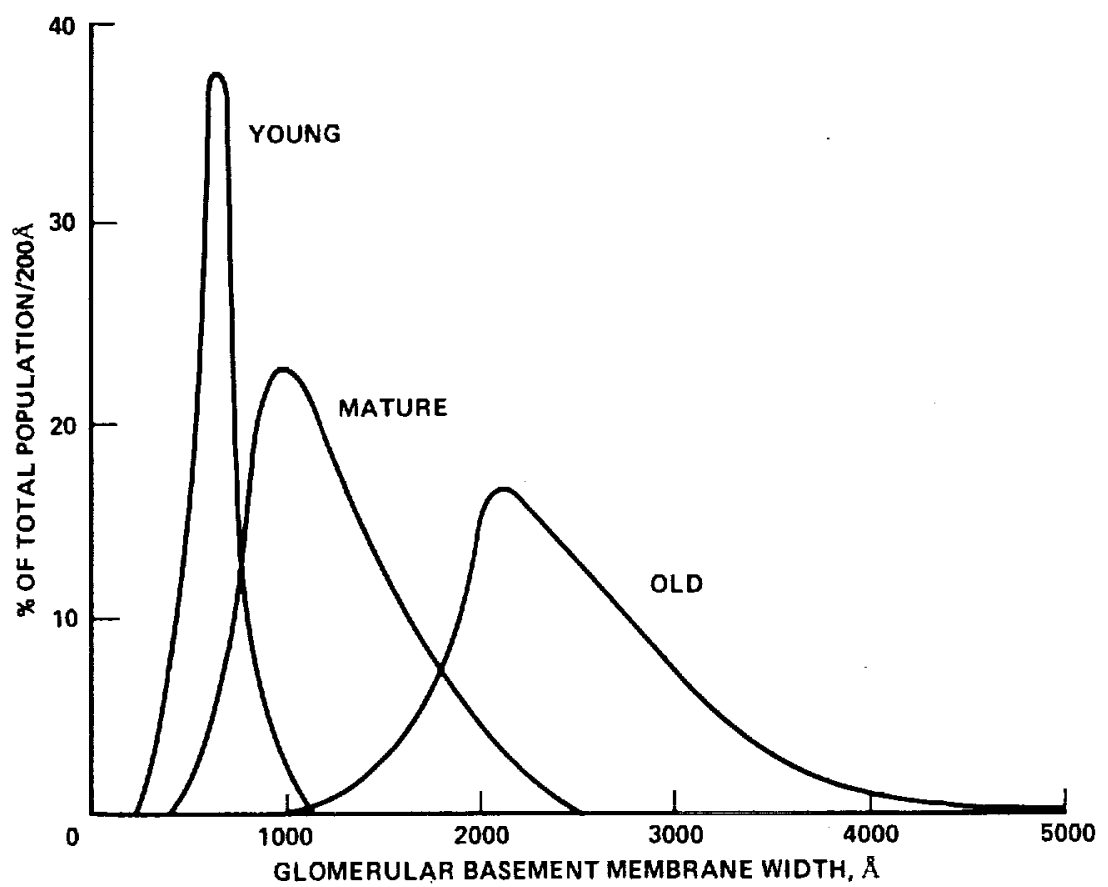

Figure 6. Frequency distribution of width of glomerular basement membrane of hamster kidneys at three different ages: 0,19 , and 70 weeks. Redrawn from McNelly and Dittmer (1976).

(a)

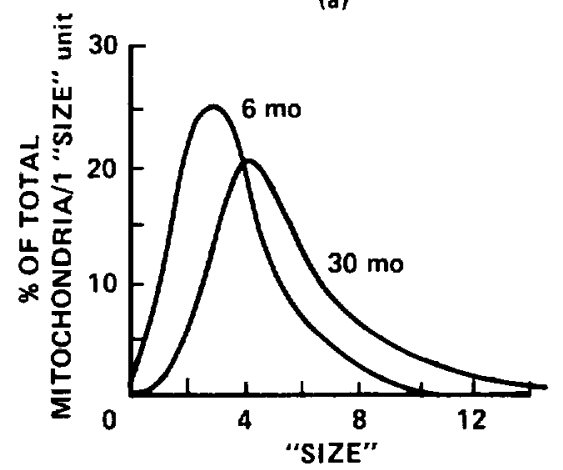

(b)

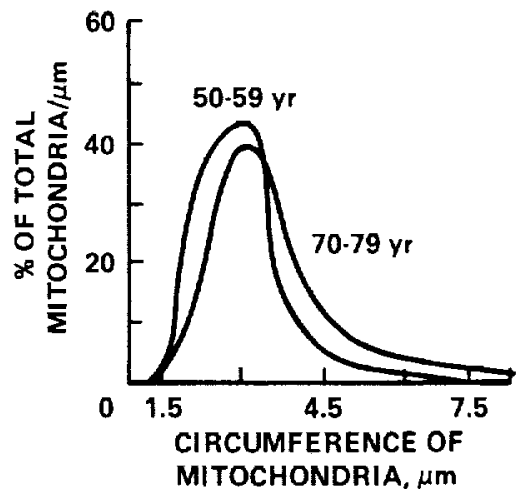

Figure 7. Effect of age on ultrastructural characteristics. (a) Relative size of mitochondria in cells of perfused livers of young and old C57BL/6J mice. From Wilson and Franks (1975), smoothed histograms from Fig. 6. (b) Circumference of mitochondria in human liver cells in two age groups. From Tauchi and Sato (1968), smoothed histograms from Fig. 4. 


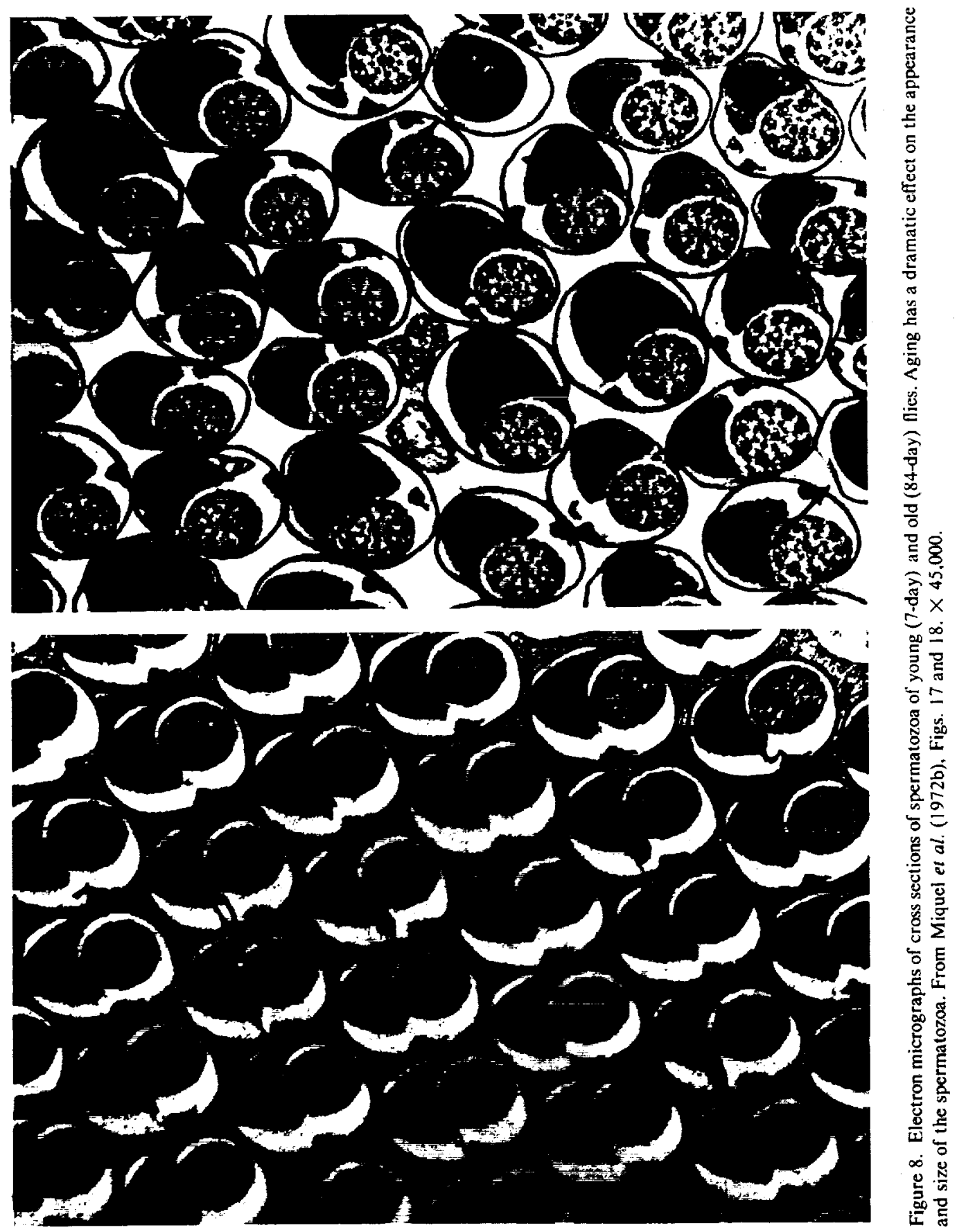



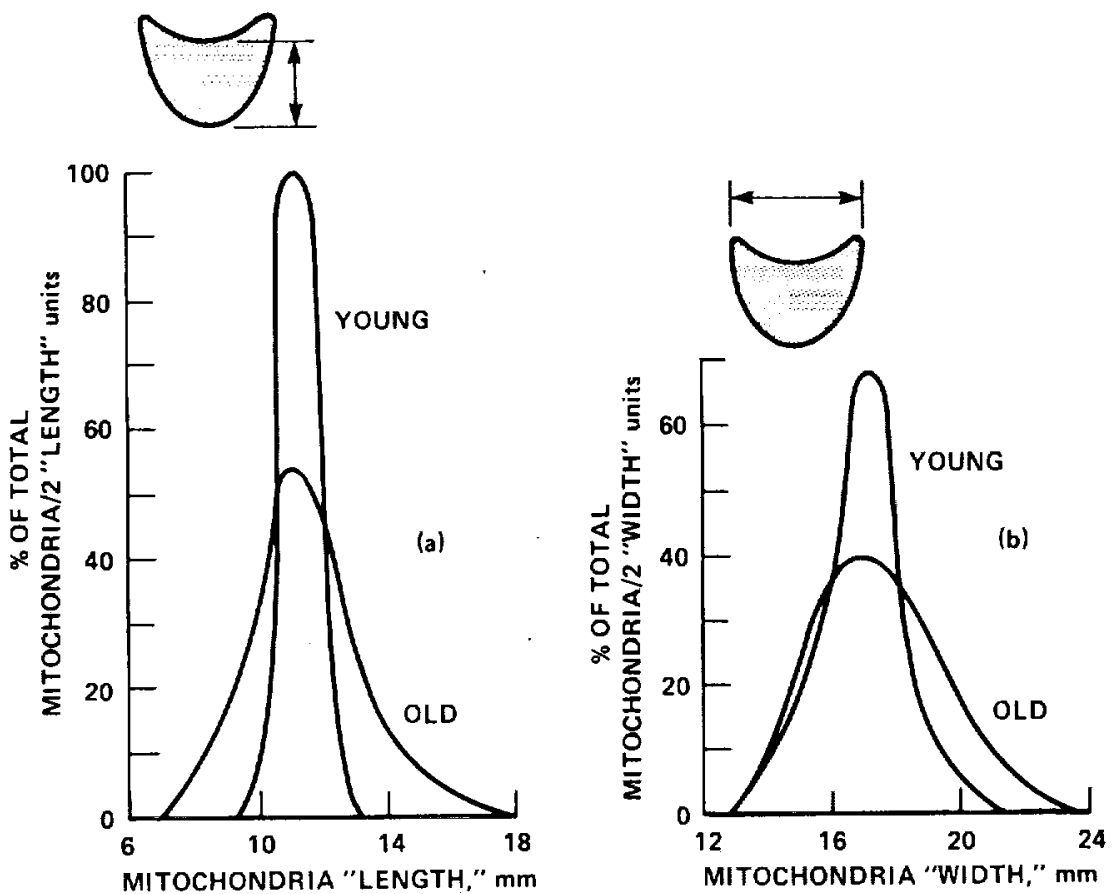

Figure 9. Frequency distribution of "length" and "width" of the mitochondria of the spermatozoa of young and old fruit flies measured manually on the electron micrographs of Fig. 8. ("Length" and "width" were measured as shown.) Aging has a striking effect on the distributions, increasing considerably their asymmetry and variance.

unchanged, unlike in the biological example. This discrepancy probably stems from the fact that the capacitors were assumed to "age" uniformly (equal increases of the number of flaws in all "individuals"), whereas aging may not progress uniformly in aging organisms.

An intriguing contrast with the examples of Figs. 6 and 10 is seen in Fig. 11. At first sight, the frequency distributions of salaries for assistant, associate, and full professors (presumably young, mature, and middle-age and older individuals, respectively) are very similar to the distributions of the glomerular basement membrane width of hamster kidneys at corresponding ages (Fig. 6). The similarity extends to both a shifting of the distribution and an increase in variance with age. However, unlike in the biological-structure example, where shifting is toward less optimal values, in the example of professorial salaries the trend is reversed! Clearly, this state of affairs does not correspond with aging changes in underlying biological structure and function; it may be an example of the effect of memory and learning (experience, information acquisition and processing in the brain) in human affairs. 

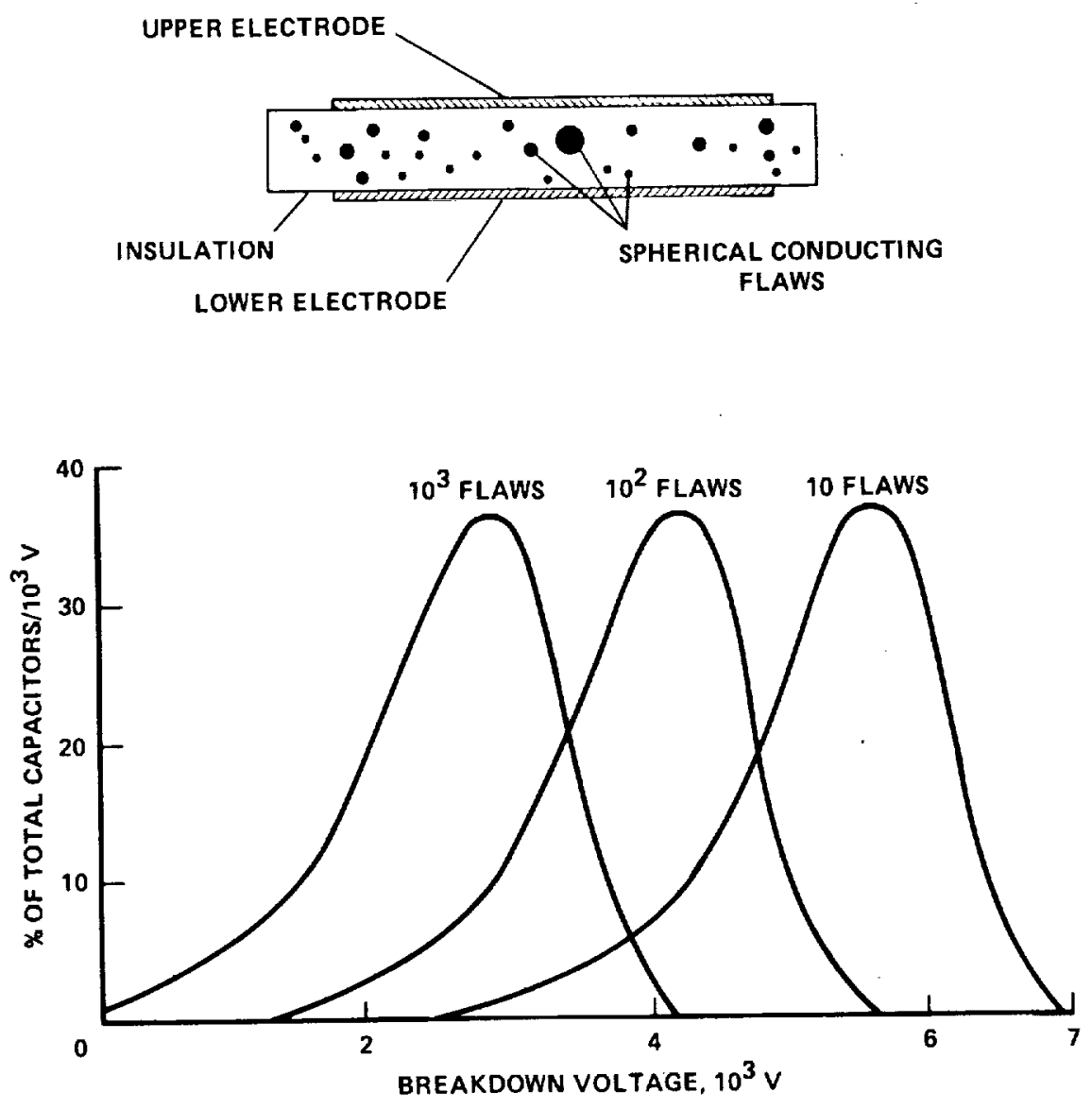

Figure 10. A "simulated-aging" effect on the frequency distribution of breakdown voltage in batches of capacitors. Aging is simulated by considering batches of capacitors with increasing numbers of conducting flaws in the dielectric. (Top) Cross section of a capacitor. From Haviland (1964), redrawn from Figs. 6.1 and 6.4 .

\section{APPLICATIONS}

\subsection{Variation in Mouse Liver Cellular and Fine Structure: Effects of Aging. Alcohol, and Antioxidants}

Andrew succinctly stated that “... histological changes [in aging] are common enough to lead us to anticipate that he who seeks frequently would find changes in ultrastructure" (Andrew, 1968). Apparently, this fact has been appreciated, for instance, by a number of investigators who have studied liver cell ultrastructure in human subjects, mice, and rats over the past two decades (Tauchi and Sato, 1962; 


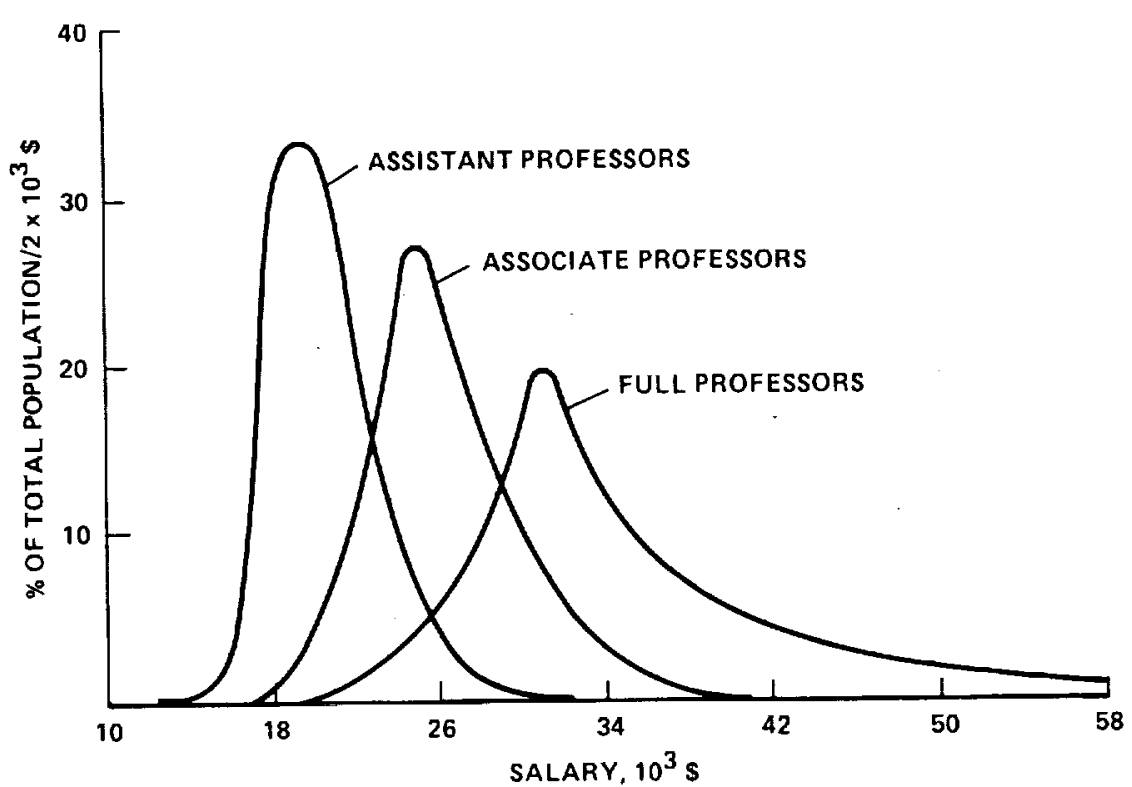

Figure 11. Frequency distribution of salaries of professors in Departments of Physiology of American universities. From Ganong (1977), smoothed histograms.

Andrew, 1962; Schmucker et al., 1974; Wilson and Franks, 1975; Pieri et al., 1975; Schmucker and Jones, 1975; Herbener, 1976; Tate and Herbener, 1976). In a previous report by our group (Johnson et al., 1978), the effects of aging and antioxidants on the fine structure of the mouse hepatocyte were described qualitatively. Here we present a quantitative analysis that illustrates application of the concepts discussed above in histology and aging. (A preliminary summary was reported in Economos et al., 1979b.)

We studied five groups of male C57BL/6J mice: 8- and 30-month-old controls; a group fed an antioxidant-containing diet ("diet 3"), consisting of lab chow containing $0.07 \%$ of tocopherol $p$-chlorophenoxyacetate and magnesium thiazolidine carboxylate from age 26 to 30 months; and two groups given $10 \%$ alcohol in their drinking water from age 12 to 24 months with or without the antioxidants.

Light microscopic study of liver from the various groups confirmed the finding from previous investigations that in normal aging the overall appearance of the liver parenchyma does not change dramatically (Andrew, 1962; Tauchi and Sato, 1962), apart from a loss of cells reflected in a $20 \%$ decrease of liver weight in old controls (Johnson et al., 1978). However, alcohol had considerable effects, while the antioxidant diet appeared to protect the liver cells to some extent from alcohol. These conclusions are supported by Figs. 12 and 13, which show the frequency distributions of cell sizes in the five groups (pooled data from four livers from each group, 100 cells from each liver on four different sections). The distribution of cell sizes in old controls or old animals on the antioxidant diet was similar to young controls, with a small tendency toward increased cell size that did not affect the average cell size. From observation and mea- 


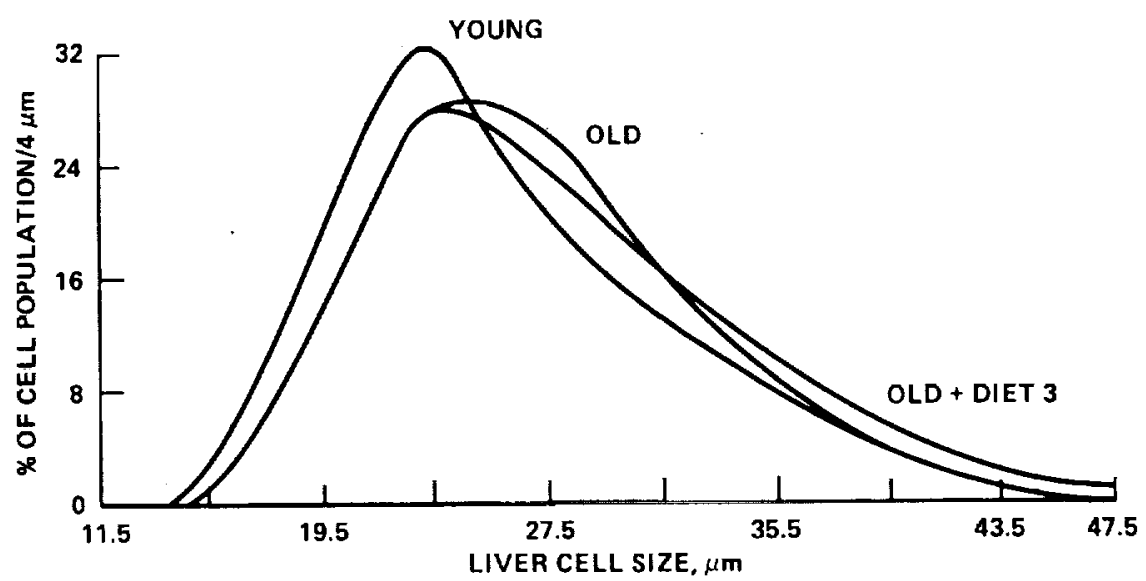

Figure 12. Effects of aging and antioxidants ("diet 3") on the frequency distribution of mouse hepatocyte size (largest diameter measured by using a light microscope)

surement of cell nuclei, it appears that the number of binucleated cells increased slightly but not significantly with age from $15.5 \%$ in young controls to $16.7 \%$ in old controls and $16.3 \%$ in old animals on the antioxidant diet (Table I). This increase was accentuated in alcohol-treated animals $(22.3 \%$ binucleated cells), with some protection by the antioxidants $(19.0 \%$ in the alcohol $+\operatorname{diet} 3$ group). Though alcohol had a very small effect on average cell size, the frequency distribution of cell sizes was dramatically affected (Fig. 13). Despite the increase in the percentage of binucleated cells, alcohol decreased considerably the percentage of larger cells, an effect that was also repressed in the group that received antioxidants plus alcohol (Table I). Finally, the average size of the nucleus increased slightly with aging, accompanied by a similar increase in the average size of the cytoplasm, the nucleocytoplasmic ratio remaining essentially

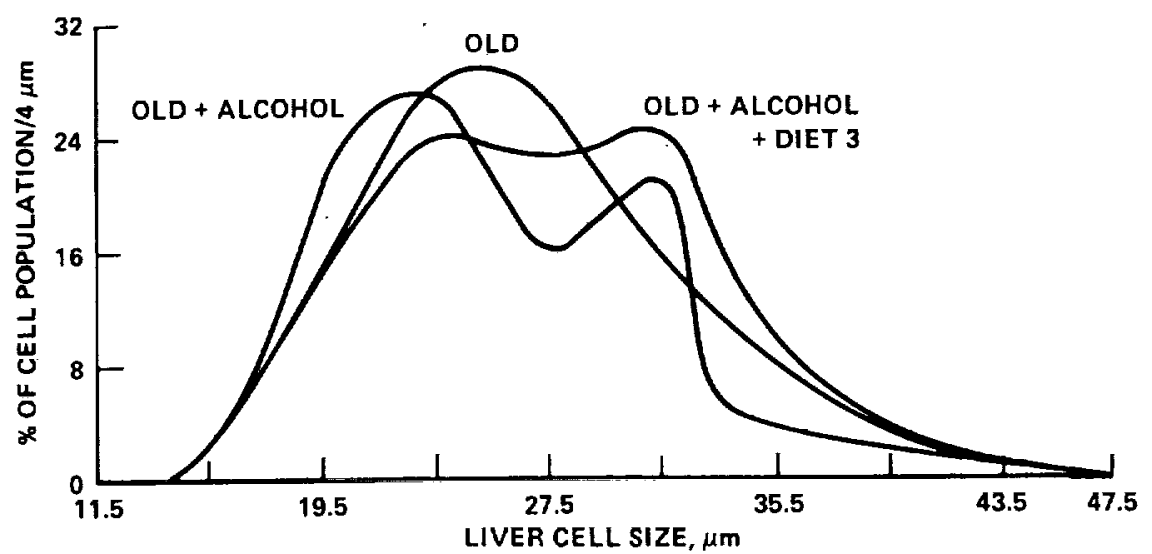

Figure 13. Effects of alcohol with or without antioxidants ("diet 3") on the frequency distribution of mouse hepatocyte size (largest diameter measured by using a light microscope). 
Table 1. Liver Cell Characteristics: Effects of Age, Alcohol, and Antioxidants ("Diet 3")

\begin{tabular}{lccc}
\hline & Average size $(\mu \mathrm{m})$ & \% of cells $\geqslant 26 \mu \mathrm{m}$ & \% binucleated cells \\
\hline Young & 25.9 & 46.2 & 15.5 \\
Old & 26.8 & 54.4 & 16.7 \\
Old + diet 3 & 27.9 & 59.6 & 16.3 \\
Old + alcohol & 25.9 & 46.2 & 22.3 \\
Old + alcohol + diet 3 & 27.2 & 60.4 & 19.0 \\
\hline
\end{tabular}

unchanged, while variance in cell sizes increased, in general agreement with findings in the aging human liver (Tauchi and Sato, 1962).

The electron microscopic study of hepatocytes in the five groups of mice has been described elsewhere (Johnson et al., 1978). Figures 14 to 16 show representative cells from control and antioxidant-treated mice. Apparently, qualitative changes of hepatocyte fine structure in aging are slight. Alcohol, however, had a dramatic effect on the fine structure of liver mitochondria, i.e., mitochondrial clustering and thinning of the mitochondrial membrane, were evident. Antioxidants seemed to repress this effect, but apparently the cells had fewer mitochondria and considerably more fat droplets. To analyze the effects of aging, alcohol, and antioxidants on hepatocyte mitochondria quantitatively, we selected at random five electron micrographs from each experimental group and measured manually the "length" $(L)$ and "width" $(W)$ of each mitochondrion (400-500 total). (When, for irregular mitochondria, a single width could not be measured, two widths were measured at about $\frac{1}{4}$ length from the mitochondrial central point and their average was used.) We then determined a rough but reasonable estimate of mitochondrial "area" $(A)$ on the micrograph as the product $L \times W$, and an estimate of one-half the mitochondrial "circumference" $(C)$ as the sum $L+W$. Frequency distributions of $L, W, A$, and $C$ were plotted for all groups and are analyzed below based on the concepts presented in this chapter.

Figure 17 shows the frequency distributions of mitochondrial length and width in three experimental groups. All distributions had an asymmetric log-normal type form. The asymmetry was the smallest for $W$ in young controls; it was somewhat larger for $W$ of old controls, a trend abolished by the antioxidant diet. The same relationship is apparent for $L$, but all $L$ distributions had a considerably larger asymmetry than the $W$ distributions. This accentuation of asymmetry in the mitochondrial length distribution may be an artifact of the measurement procedure. Indeed, the length of a mitochondrion on an electron micrograph is proportional to the product of the organelle's actual length and the angle at which the mitochondrion was cut, unlike for the width. This is due to the ellipsoid form of the mitochondrion. (This phenomenon can be better visualized by imagining a cut through a cylinder: the width of the cross section of the cylinder is equal to its actual width, but the length of the cross section depends also on the angle of the cut.) Thus, $L$, being the product of two distributed characteristics (the angle of cutting also has a frequency distribution, because it depends on the random orientation of mitochondria in the cell space), has a distribution tending toward an asymmetric log-normal type of distribution, although the actual length may have a less asymmetric distribution, comparable to that for $W$ s. 


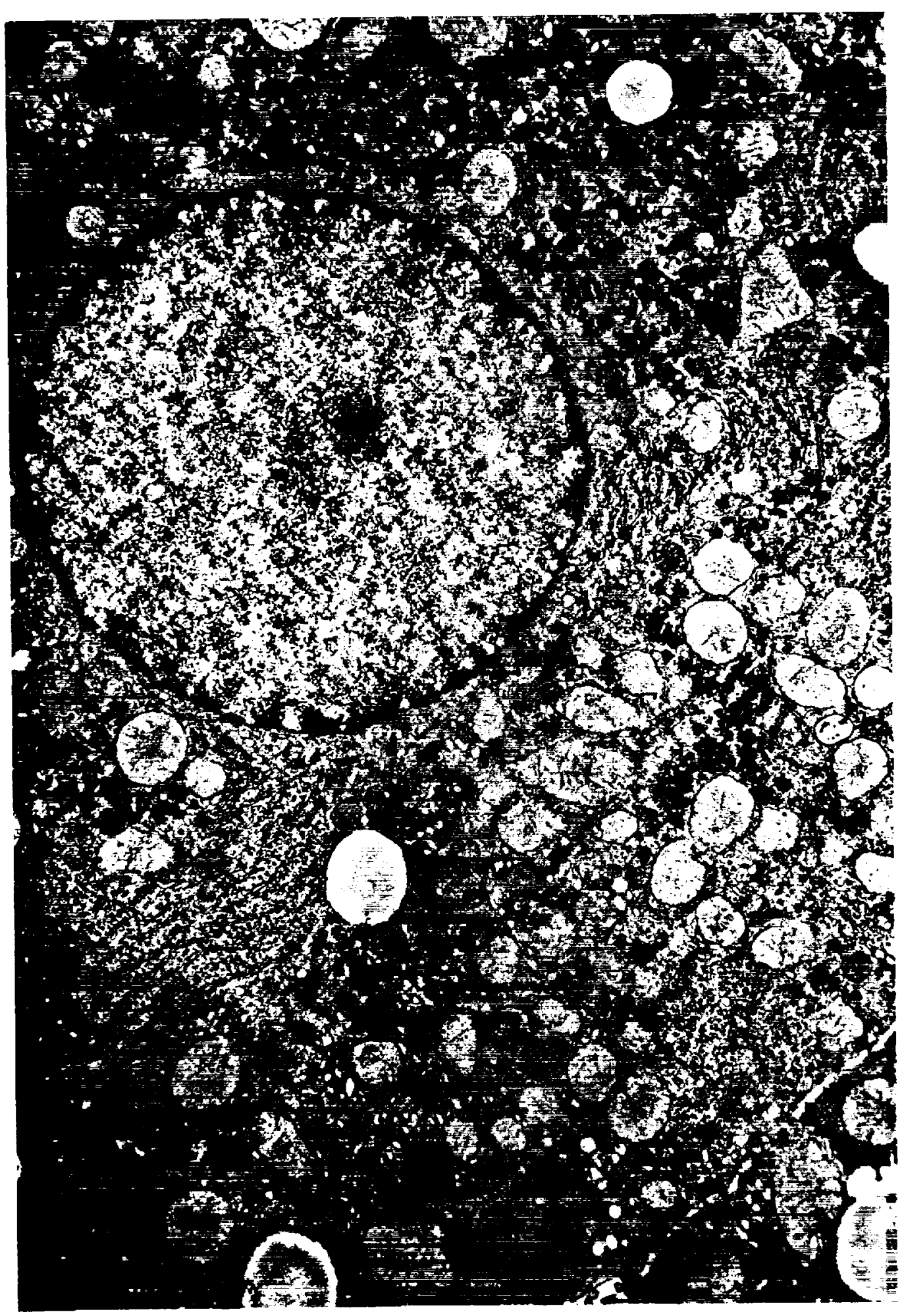

Figure 14. Electron micrograph of a hepatocyte from the liver of an 8-month-old control mouse. $\times 13,650$. 


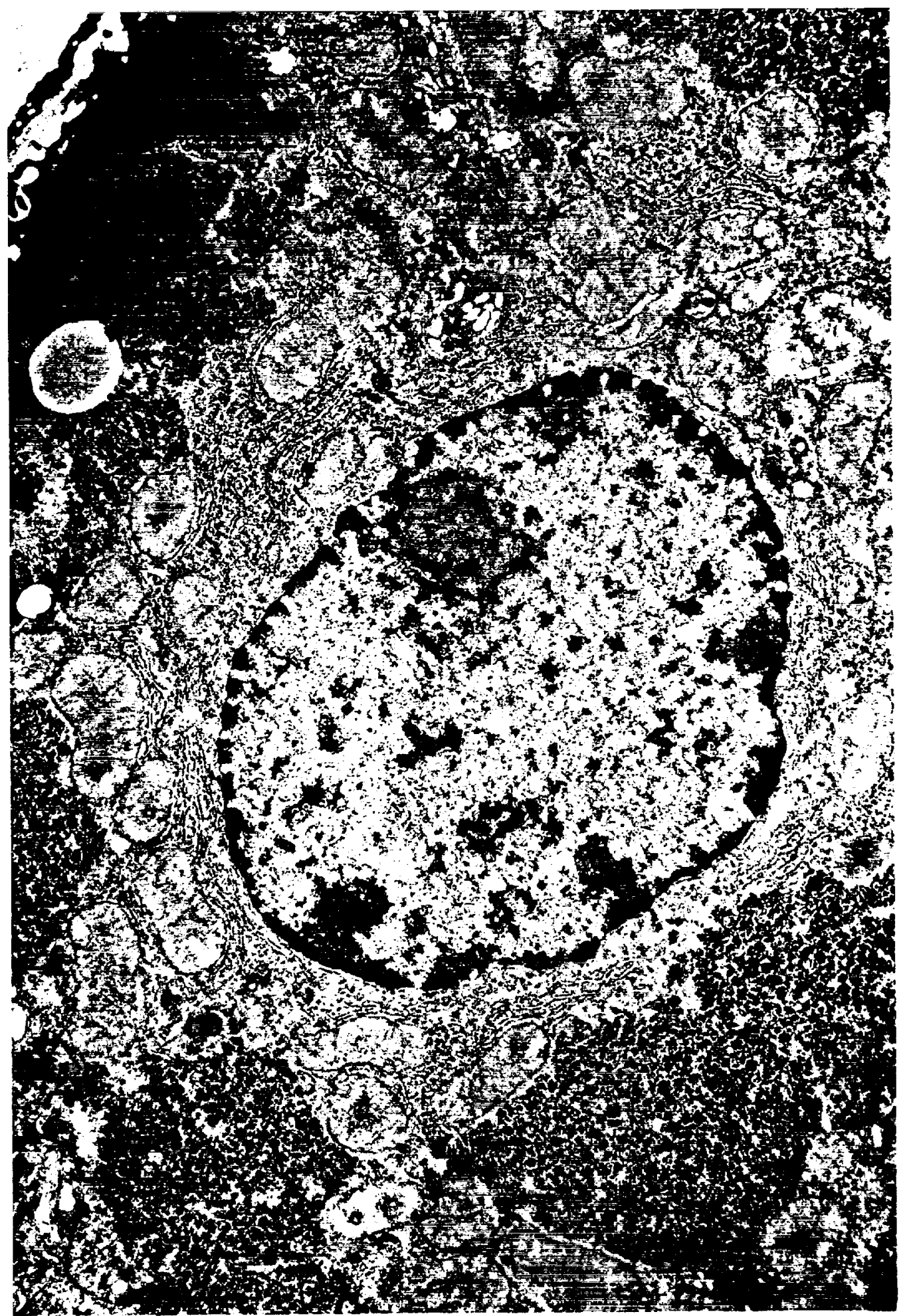

Figure 15. Electron micrograph of a hepatocyte from a 30-month-old control mouse. Notc an apparent slight increase in mitochondrial size compared with Fig. 14. X 13,650. 


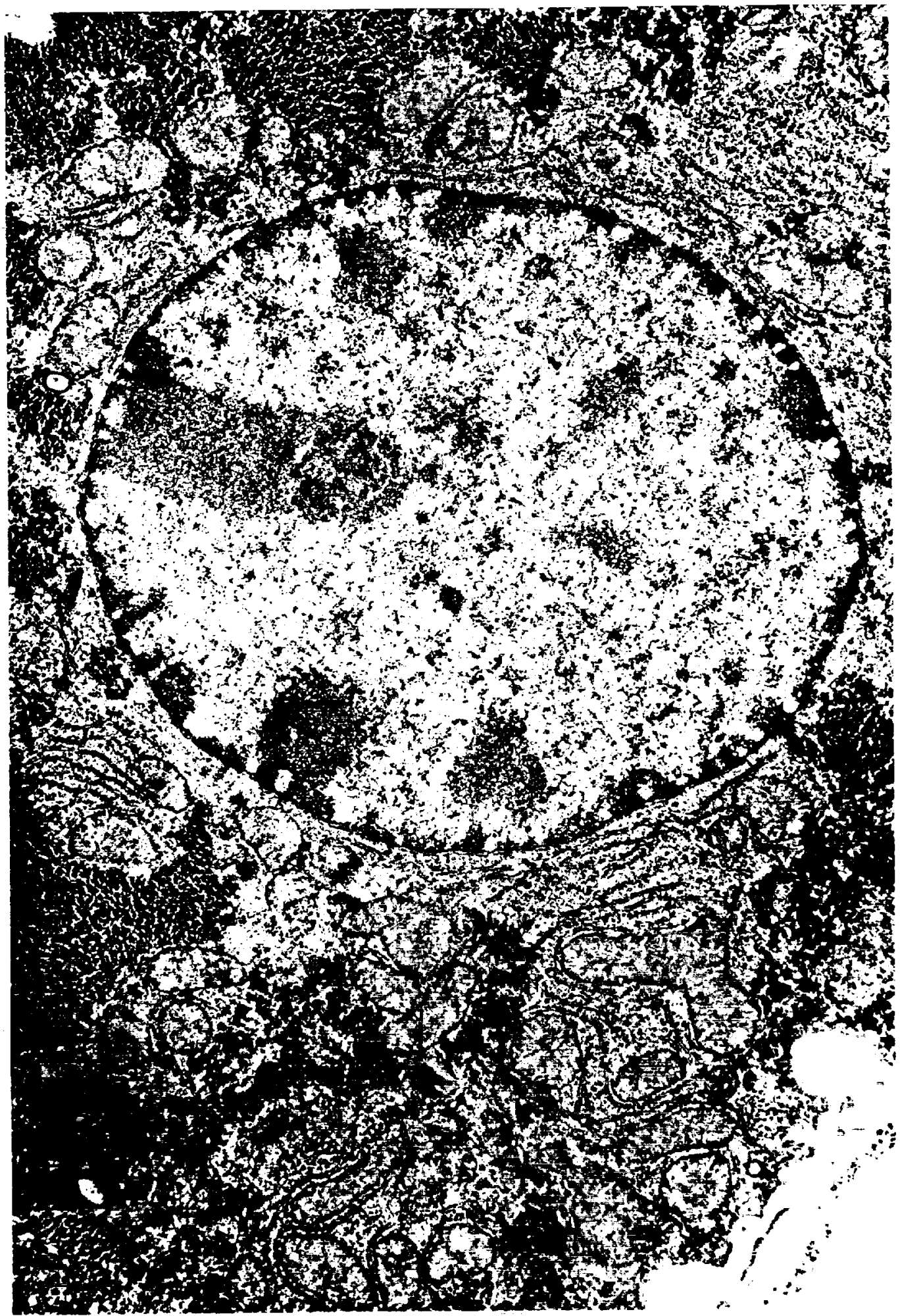



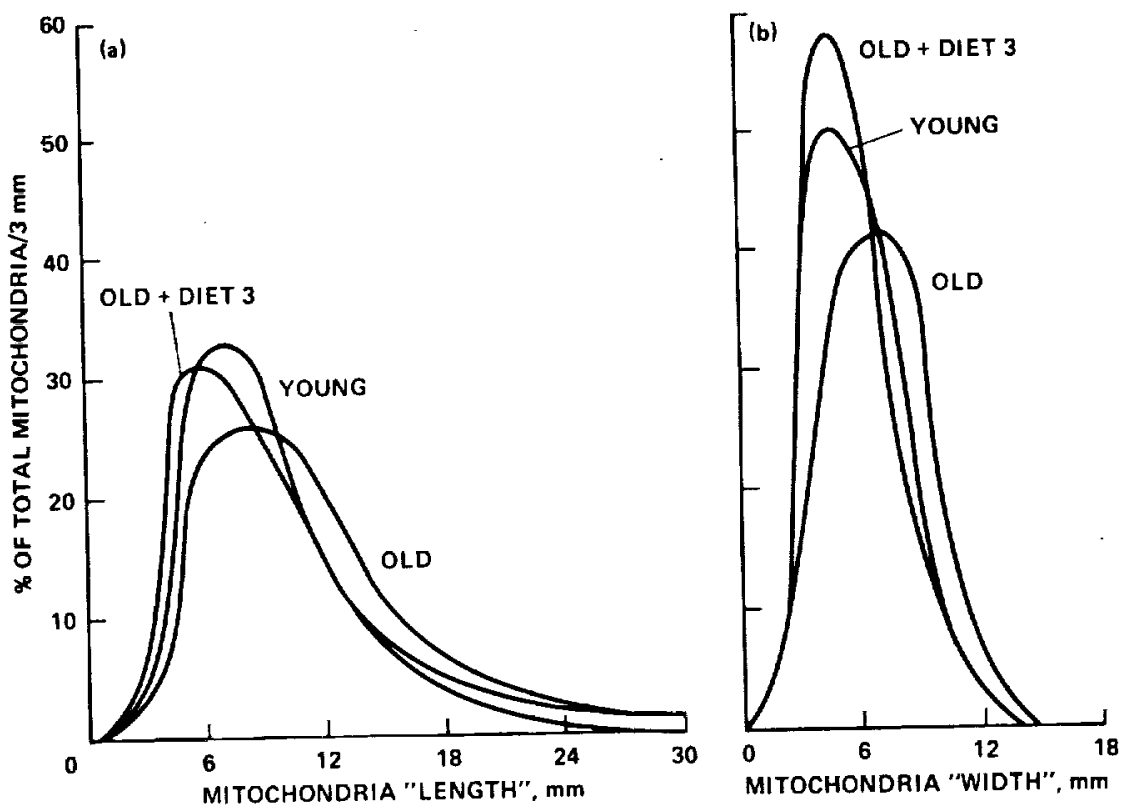

Figure 17. Effect of aging and protective effect of antioxidants ("diet 3") on the frequency distribution of mouse hepatocyte mitochondrial "length" (a) and "width" (b). ("Length" and "width" were measured on electron micrographs of hepatocytes at 13,650-fold magnification.)

Following the same reasoning, the estimated mitochondrial area, which is the product of $L$ and $W$, should have even more asymmetric distributions than either $L$ or $W$ in all groups. Figure 18 a shows this. However, the estimated circumference, being the sum rather than the product of $L$ and $W$, should have a less asymmetric distribution, in agreement with the central limit theorem, mentioned above, which dictates that the sum of distributed characteristics tends to have a bell-shaped distribution (Fig. 18b). Both area and circumference were affected by the antioxidant diet similarly to $L$ and $W$, i.e., the youthful distribution patterns were restored. These trends are clearly discerned in Fig. 19, where the frequency distributions of $L, W, L \times W$, and $L+W$ are plotted for young and old control animals separately.

Mitochondrial length and area frequency distributions are plotted for four groups (young controls, old controls, old + alcohol, and old + alcohol + antioxidants) in Fig. 20. Paradoxically, alcohol alone changed the distributions only slightly, but when antioxidants were given in the diet to protect against the effects of alcohol, the frequency distributions were further shifted or their asymmetry toward larger values was accentuated compared with the old controls and old + alcohol without antioxidants. However, as was mentioned above, alcohol had a dramatic qualitative effect on mitochondrial fine structure, probably impairing their function considerably despite a small effect on mitochondrial dimensions: the mitochondria became pathologic rather than

Figure 16. Effect of the antioxidant diet on hepatocyte fine structure in a 30-month-old mouse; the tendency to increased mitochondrial size caused by aging is repressed by the diet. $\times 13,650$. 

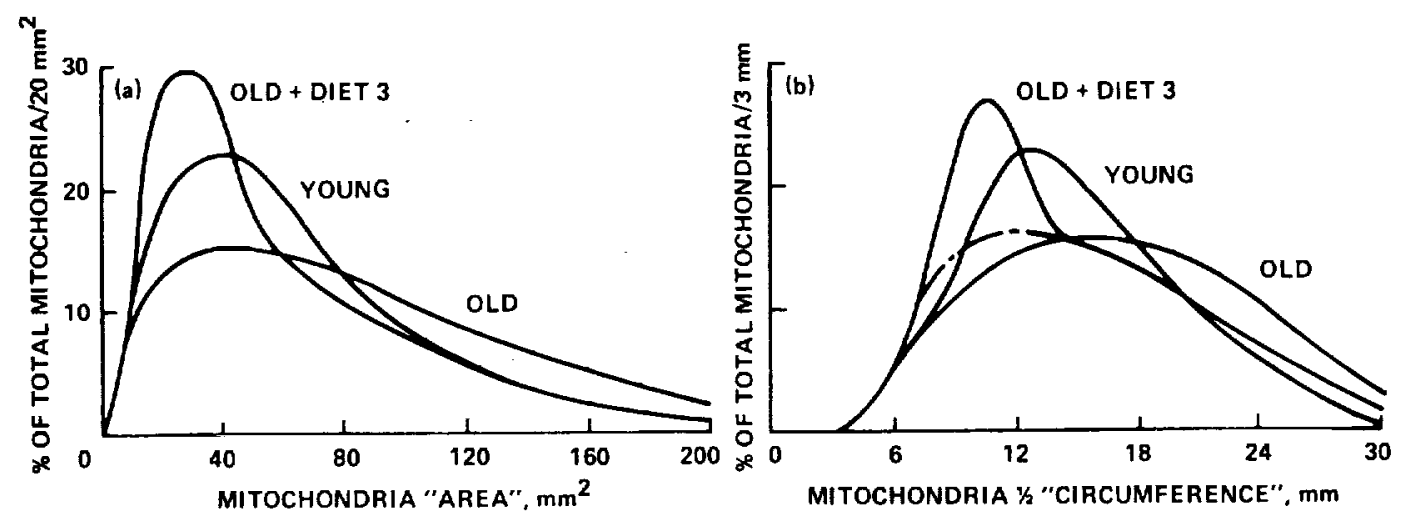

Figure 18. Effect of aging and protective effect of antioxidants ("diet 3") on (a) estimated mitochondrial "area" ("length" $X$ "width") and (b) estimated one-half mitochondrial "circumference" ("length" + "width").
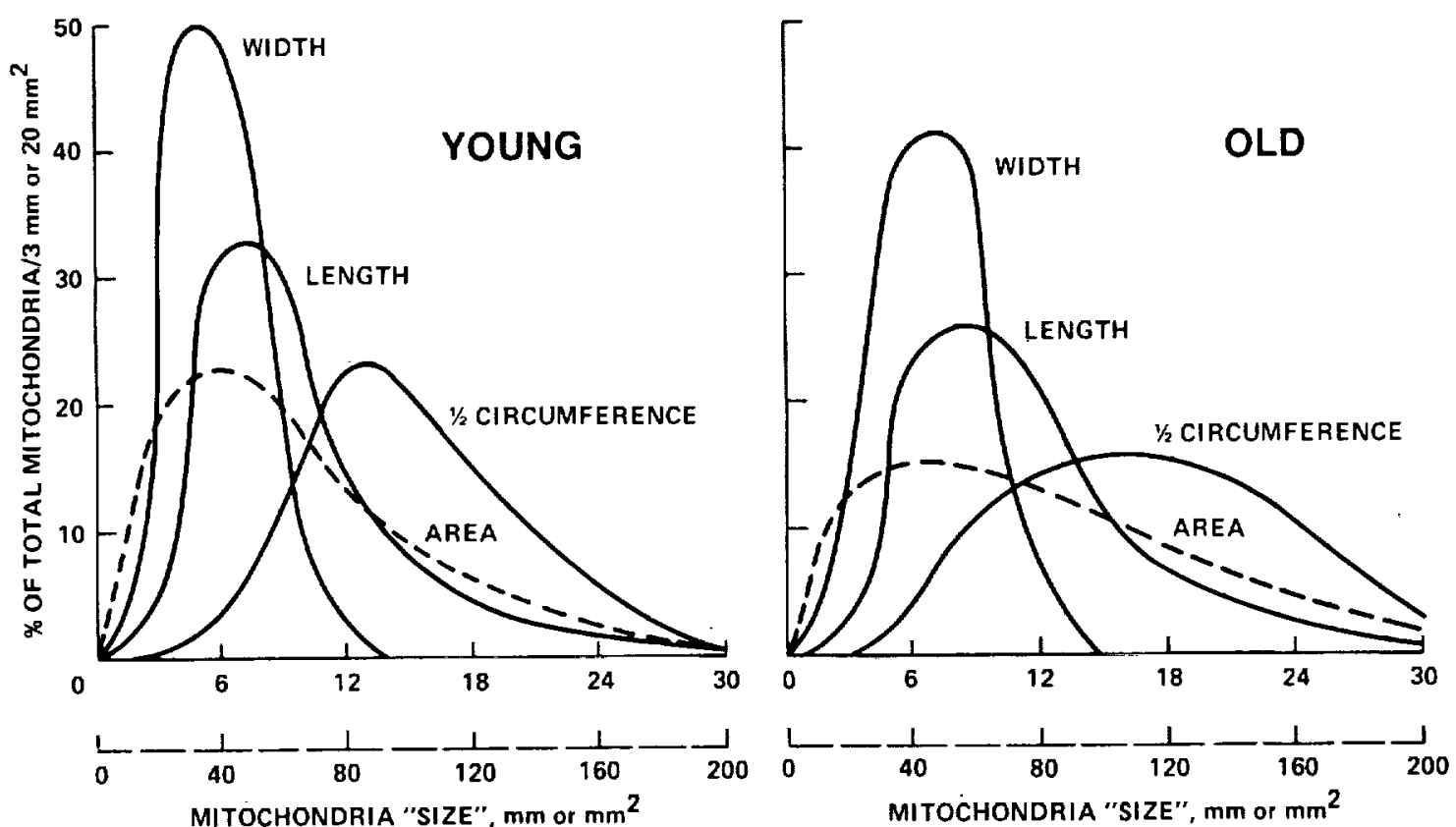

Figure 19. Frequency distributions of mitochondrial "length," "width," "area," and "circumference" are plotted on the same graph for young and old mice, to compare the various distributions at the same age.

aged faster. The antioxidant diet may have partially protected the mitochondria against this effect of the alcohol, but the cells now had fewer mitochondria (fewer but "healthier"?); the increased fat-droplet volume would make up for the lost mitochondria. Therefore, because alcohol appears to damage mitochondrial fine structure (and probably function) considerably, the morphometric analysis cannot be applied in this case. 

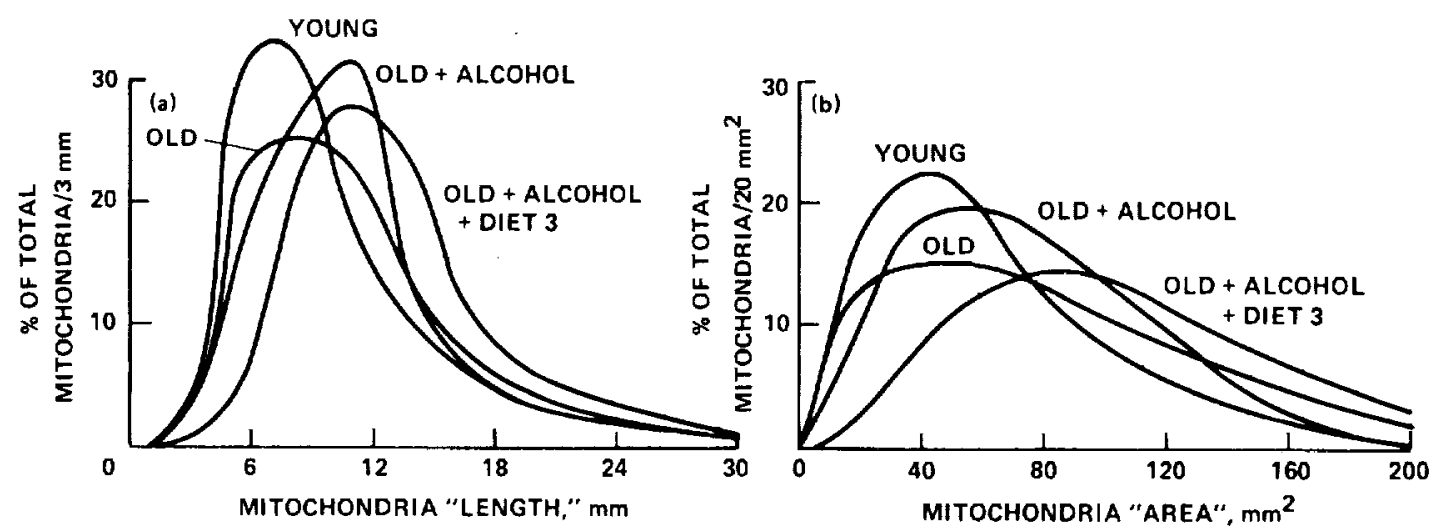

Figure 20. Frequency distributions of (a) "length" and (b) "area" of mouse hepatocyte mitochondria in four of the five experimental groups, plotted on the same graphs to show the effect of alcohol.

The qualitative electron microscopic evidence and the quantitative analysis of light microscopic information that showed virtual elimination of larger cells by the alcohol, an effect repressed by the antioxidants (Fig. 13), indicate that the antioxidant diet protected the mitochondria to some extent from the damaging effect of high levels of alcohol in mice.

\subsection{Variation in Vitality and Mortality}

The individuals of a cohort die at different ages, even in inbred strains of animals. Typical frequency distributions of ages at death were shown in Fig. $4 \mathrm{c}$ and d. Previous theories of mortality have generally assumed that the individuals of a population are identical and have sought to explain the variation in age at death based on various assumptions on the statistical properties of the causes of death. However, variation in constitutional and functional characteristics of individuals is a reality that should not be suppressed. Even more, it is shown elsewhere (Economos and Miquel, 1979) that variation in mortality and physiological characteristics are closely related. The model is summarized below.

A physiological variable measured over the individuals of a population has a frequency distribution typified by latency of first mating of flies (Fig. 3a). A number of physiological functions can be chosen that are important for survival to a given extent. A weighted sum of these variables in accordance with their relative importance will have a similar frequency distribution. This sum, called vitality, may be considered to reflect an individual organism's capacity to resist death. Because most physiological functions decline uniformly with age (Shock, 1960), so will the vitality of each individual, the form of its frequency distribution remaining roughly unchanged with age. Therefore, the distribution of ages at death can be derived by a linear transformation of the distribution of vitalities (Fig. 21). If the distribution of vitality is changed, e.g., by eliminating weak or unfit individuals through a physical examination, the distribution of ages at death and mortality kinetics will change accordingly (Fig. 22). 
Figure 21. Hypothetical frequency distribution of vitality in a population and its relationship with population mortality kinetics. For the mathematical model it is assumed that the distribution stands still as the population ages, while a life-death threshold increases at $a$ rate $b$ (actually the reverse is true). At each age $t$, total mortality will be proportional to the area under the vitality curve below the life-death threshold. (For a detailed description of this model, see Economos and Miquel, 1979.)

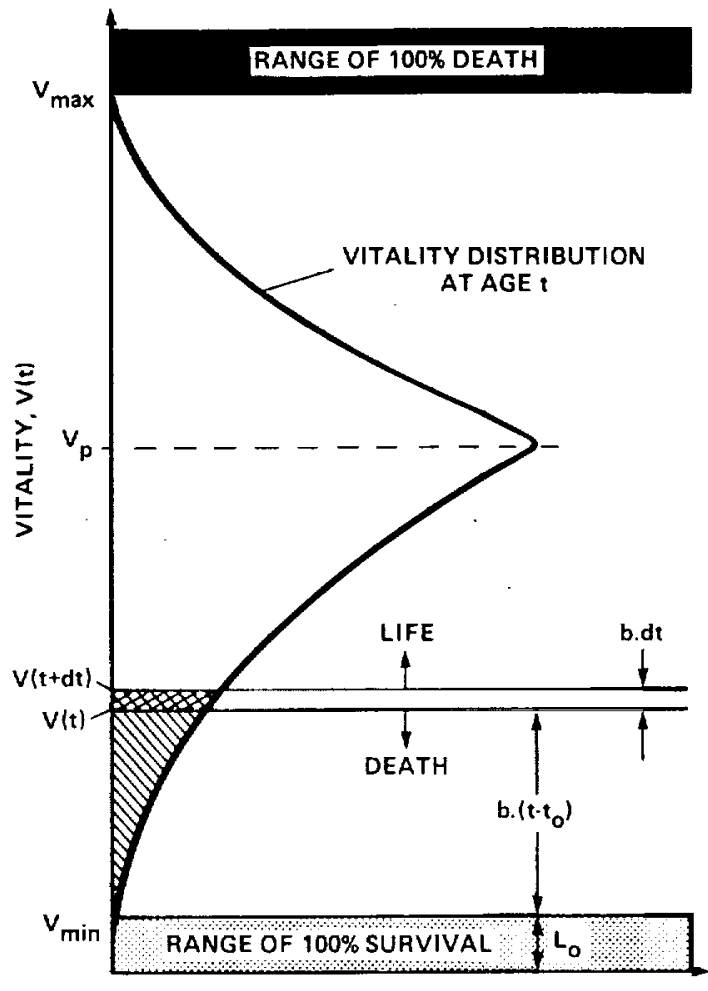

NUMBER $N(V(t))$ (a)

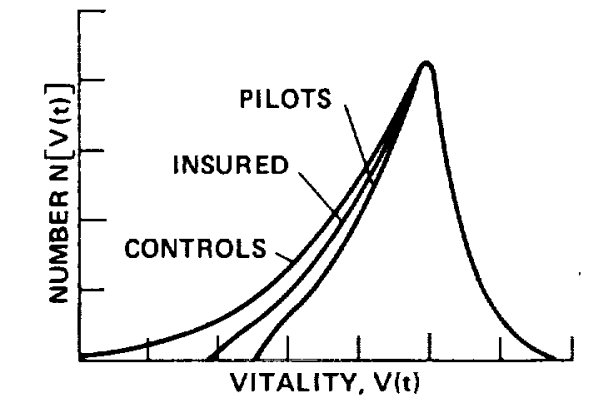

(b)

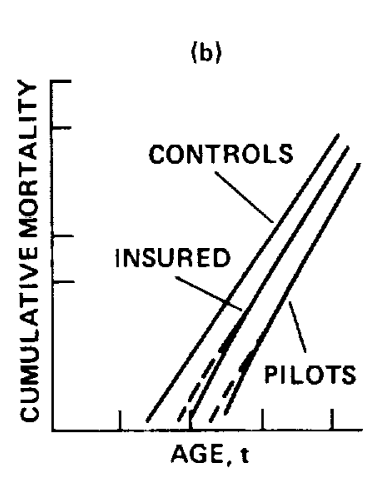

Figure 22. Schematic representation of changes in vitality distribution caused by selection through a physical examination of the "healthier," more fit individuals (medically insured persons and pilots), and predicted effects on mortality kinetics, which agree with observations. From Economos and Miquel (1979). [Cumulative mortality is plotted semilogarithmically, as proposed by Economos (1979a).]

\subsection{Time-Condensing in Experimental Aging Research through the Study of Variation}

An important shortcoming of the classical actuarial methodology used in applied aging research, where the effect of environmental factors and dietary chemicals (aging 
rate modulators) is assessed in terms of effects on mortality kinetics, is well known: the experimental animals of choice (mice and rats) live too long. It is therefore imperative to have a methodology that will enable us to predict the effects on life span in a much shorter time than the $2 \frac{1}{2}$ and $4 \mathrm{yr}$ that are the average and maximal life spans of mice and rats. This is the meaning of "time-condensed studies" (Economos and Miquel, 1977). Two approaches are conceivable:

1. Evaluate the effect of an aging rate modulator on the frequency distribution of a vitality variable of an experimental population by comparing with a genetically similar control population over an appropriate period of time (a fraction of the life span). From this comparison, an estimate for the effect of the aging rate modulator on aging and life span can be derived.

This approach is based on the hypothesis, substantiated above, that the frequency distribution of ages at death can be derived by a linear transformation of the distribution of vitality of the individuals at young adult age (before death sets in). Vitality was assumed to depend on a number of vitality variables important for survival. A single vitality variable may not by itself be a good "predictor" of mortality; however, if such a variable is sufficiently "integrated," i.e., depends on many other physiological and biochemical functions, then such a variable may have a predictive value. Several conditions have to be met, however. The tested aging rate modulator should have no specific effect on the vitality variable, but a general effect on the body functions on which the variable depends. It should be a relatively simple matter to measure the variable in a large population, to avoid exchanging "labor for time." The method of measurement should be noninvasive. And, of course, it should be demonstrated first that in control populations, aging with simple passage of time affects the frequency distribution of vitality in a uniform and predictable way.

It can be shown that in populations of adult mice, body weight is a vitality variable that meets these criteria (Economos and Miquel, 1980). Figure 23 shows the distribution of body weight in a population of 125 male mice at various ages. A log-normal pattern is apparent. These mice were fed "soft" lab chow ad libitum. A population of 45 male mice fed harder lab chow exhibited a less asymmetric distribution, with no overweight mice (Fig. 24); possibly, the hardness of food acted as a restraining factor that effected a tighter control of body weight. This group of mice was followed through very old age: apparently, after the age of about 24 months, the death rate begins to accelerate; the frequency distribution changes continuously in a poorly defined way. Therefore, body weight can be used as a vitality variable only in the period 8-24 months. Studies illustrating the predictive value of body weight are documented elsewhere (Economos and Miquel, 1980). Figure 25 shows one example. Here, the change of the frequency distribution of body weight of a group of mice over a 6-month period during which they were fed an antioxidant-enriched diet, is compared with a change observed in a group of control mice. The change in the experimental group results from the "slimming-out" of practically all overweight mice, which is considered to be a favorable effect. This correlated well with a small favorable effect of the diet on average life span (Economos and Miquel, 1980).

2. Develop a method to estimate the area under the frequency distribution curve of a suitable vitality variable, defined in such a way that only individuals with a vitality 

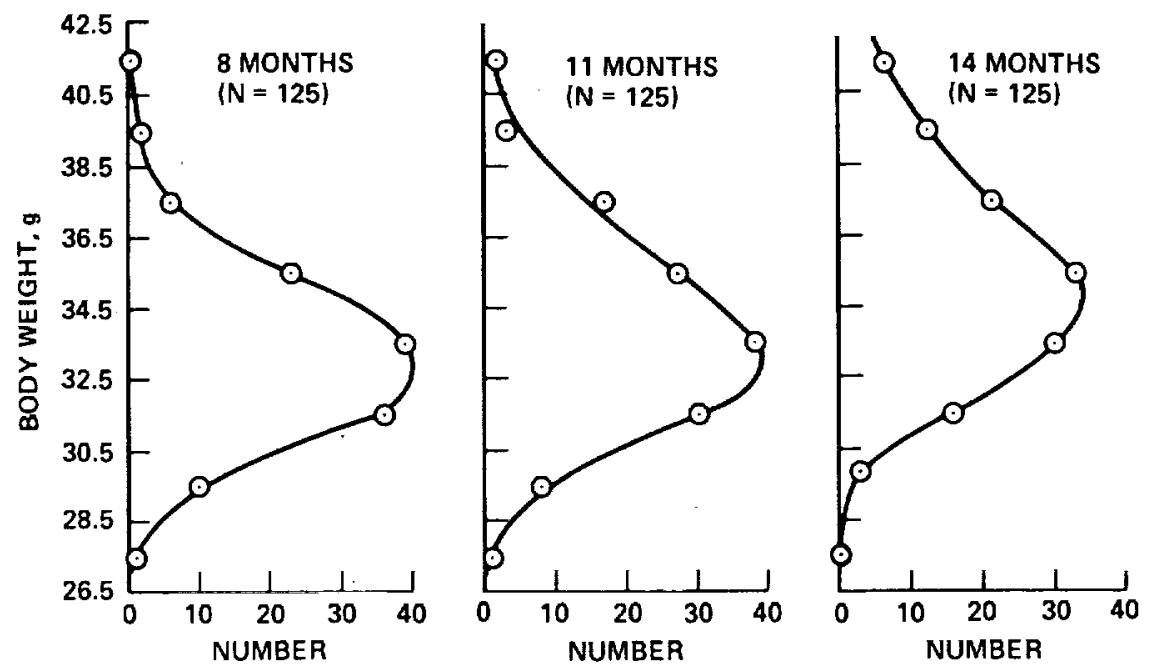

Figure 23. Age profile of body weight frequency distribution in a population of male mice fed "soft" lab chow ad libitum. From Economos and Miquel (1980).
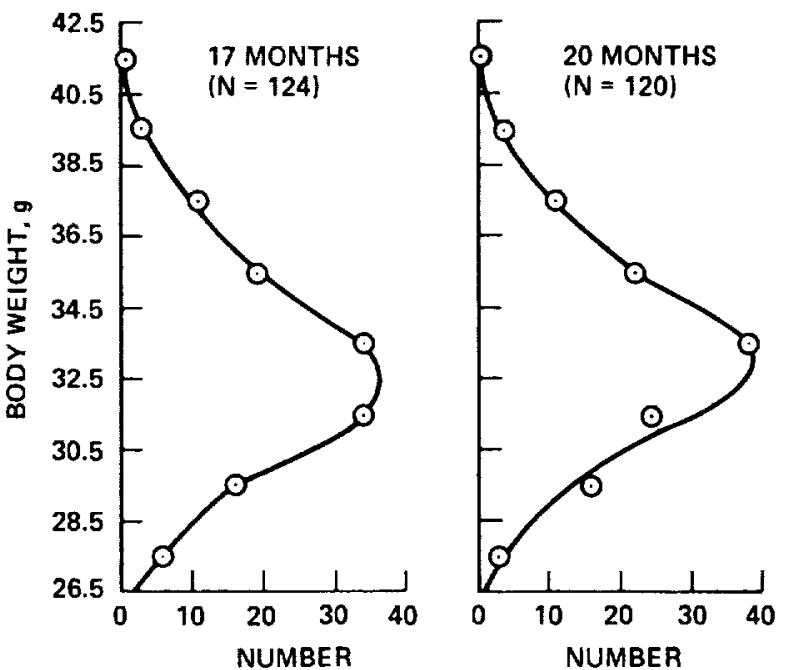

value above a certain threshold when tested in early adulthood should be included (Fig. 26 , top). A suitable vitality variable is, for instance, neuromuscular coordination, which can be estimated in simple ways both in fruit flies and in mice (Miquel et al., 1972a; Miquel and Blasco, 1979; Economos, 1979b). As the vitality frequency distribution changes with age (mainly shifting toward lower values and having larger variance), the percentage of individuals with vitality above the selected threshold decreases. It can be shown (Economos, 1979b) that if this percentage is plotted vs. age, a curve roughly parallel to survivorship is obtained (Fig. 26, bottom), the parallelism being closer the more integrated the vitality variable, i.e., the larger the number of variables on which it depends. Again, aging rate modulators can be expected to affect both the vitality curve and the survivorship curve of an experimental population in a similar way. How- 
ever, because the vitality curve precedes the survivorship curve by up to $40 \%$ of the maximal life span, a time-condensing effect is achieved. Unlike in the first approach above, this method is suitable also during the latter part of the life span when there is a large death rate.

Figure 27 illustrates the application of this approach in the study of the effect of two environmental factors on aging and life span of populations of fruit flies. As a vitality variable we used neuromuscular coordination. At each age, the population vitality (in a longitudinally studied population) was assessed based on the negative geotaxis drive of fruit flies (Miquel et al., 1972a). Clearly, under both levels of each of the two environmental factors tested, the selected vitality variable was a good predictor of survivorship. Finally, Fig. 28 illustrates the application of this approach to mice. On the
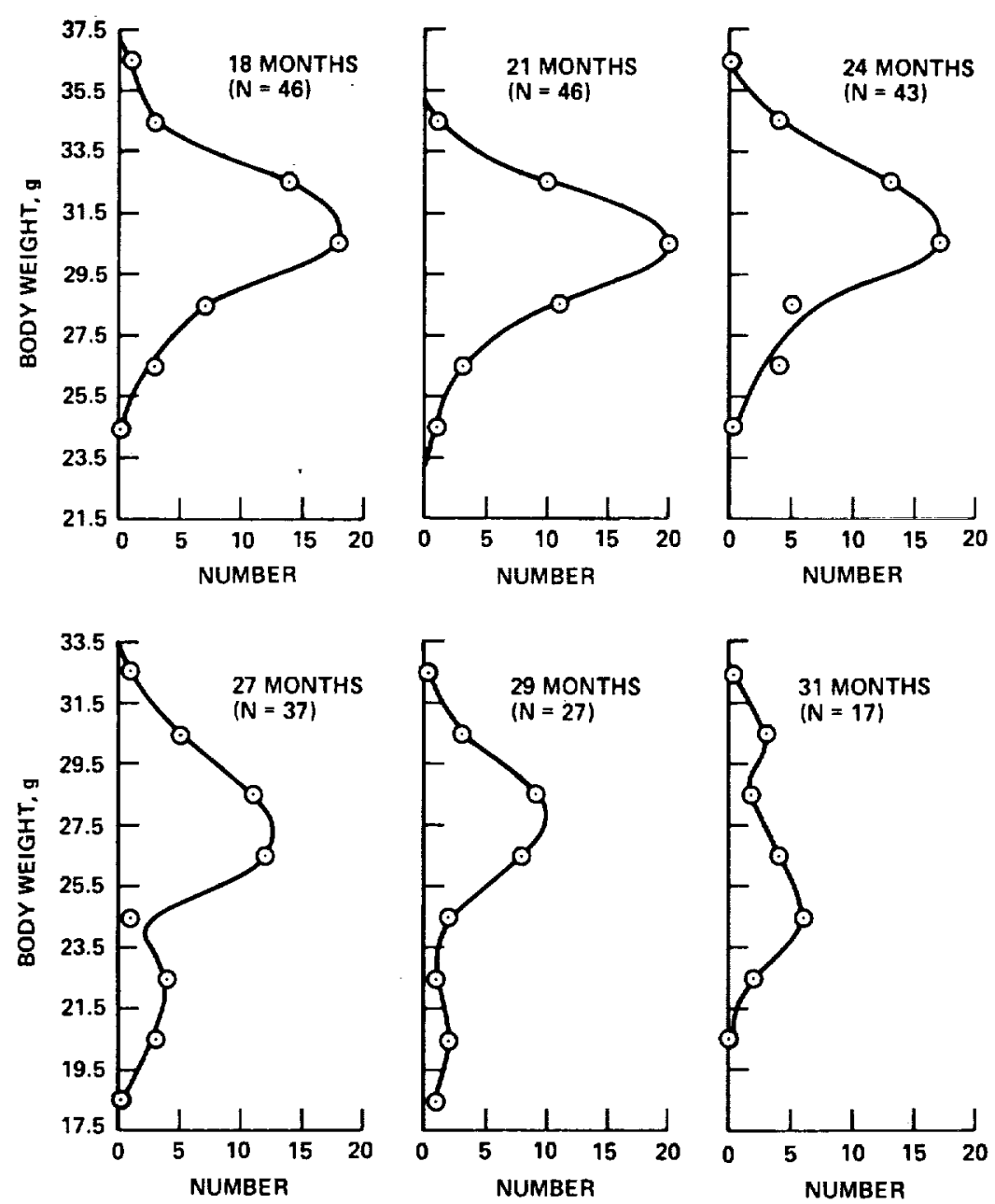

Figure 24. Age profile of body weight frequency distribution in a population of male mice fed "hard" lab chow. From Economos and Miquel (1980). 


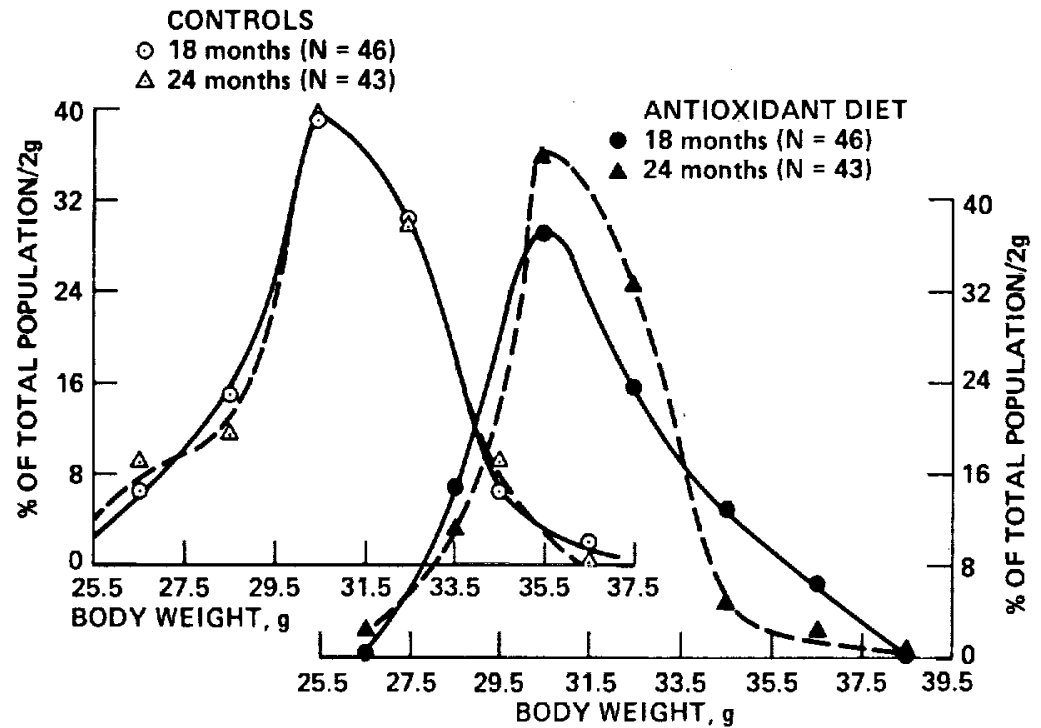

Figure 25. Effect of antioxidant diet on frequency distribution of body weight over a 6-month period. From Economos and Miquel (1980).

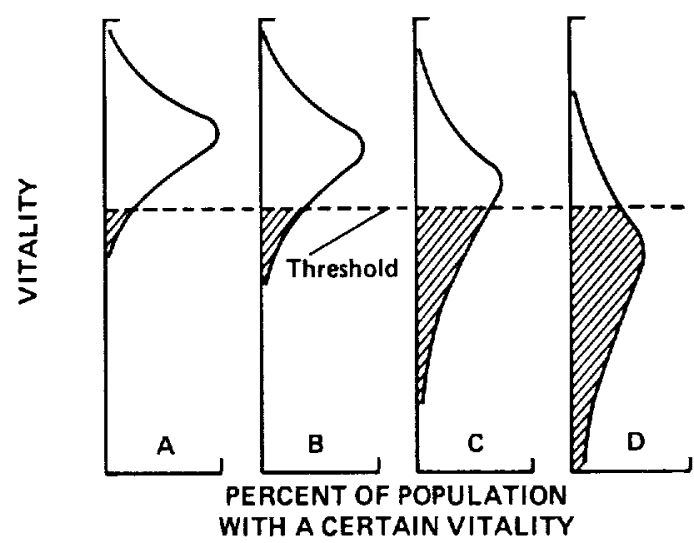

Figure 26. Top: Schematic representation of the age profile of the frequency distribution of a vitality variable in a given population. [Drawn based on data on latency of first mating in fruit flies from Economos et al. (1979a); see also Fig. 3a.] Bottom: Percentage of population with vitality above a threshold value (nonhatched area under vitality distribution curve and above threshold line) plotted against age; comparison with the population's survivorship curve. From Economos (1976b).

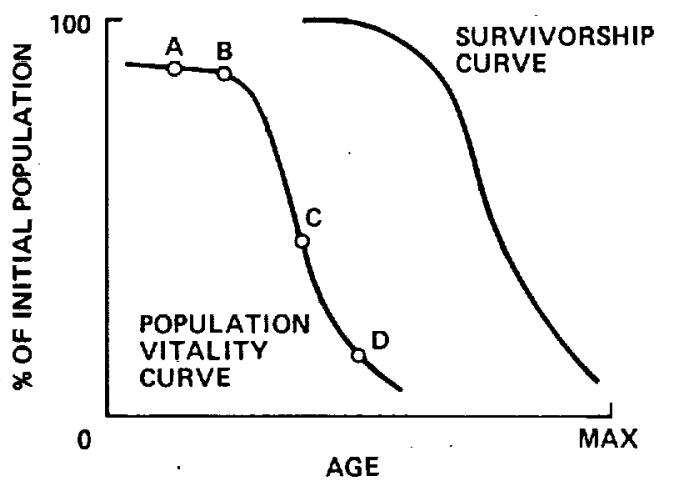



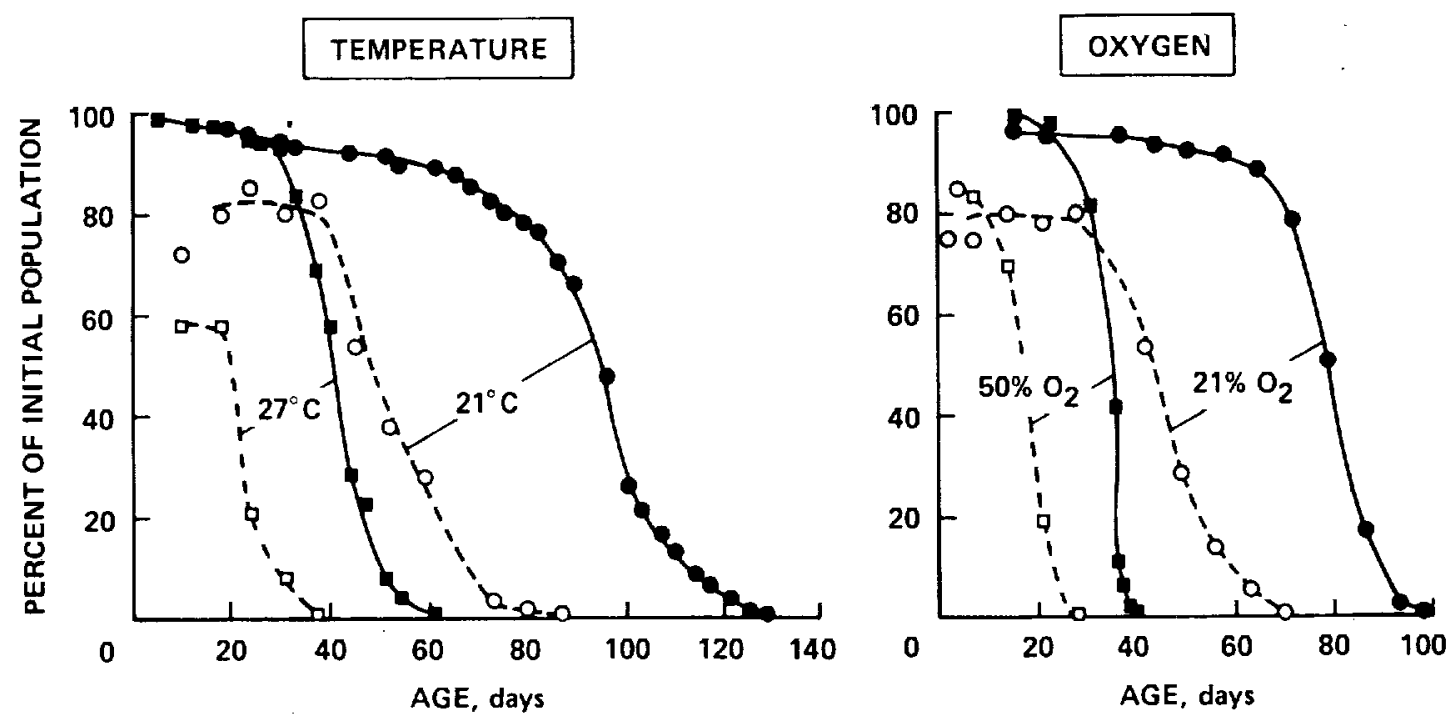

Figure 27. Population vitality curve in fruit fies as predictor of the population's survivorship curve at two levels of two environmental factors. Vitality is here neuromuscular coordination assessed by the negative geotaxis test; the percentage of the population that pass the test is plotted vs. age. Data from Miquel et al. $(1975,1976)$

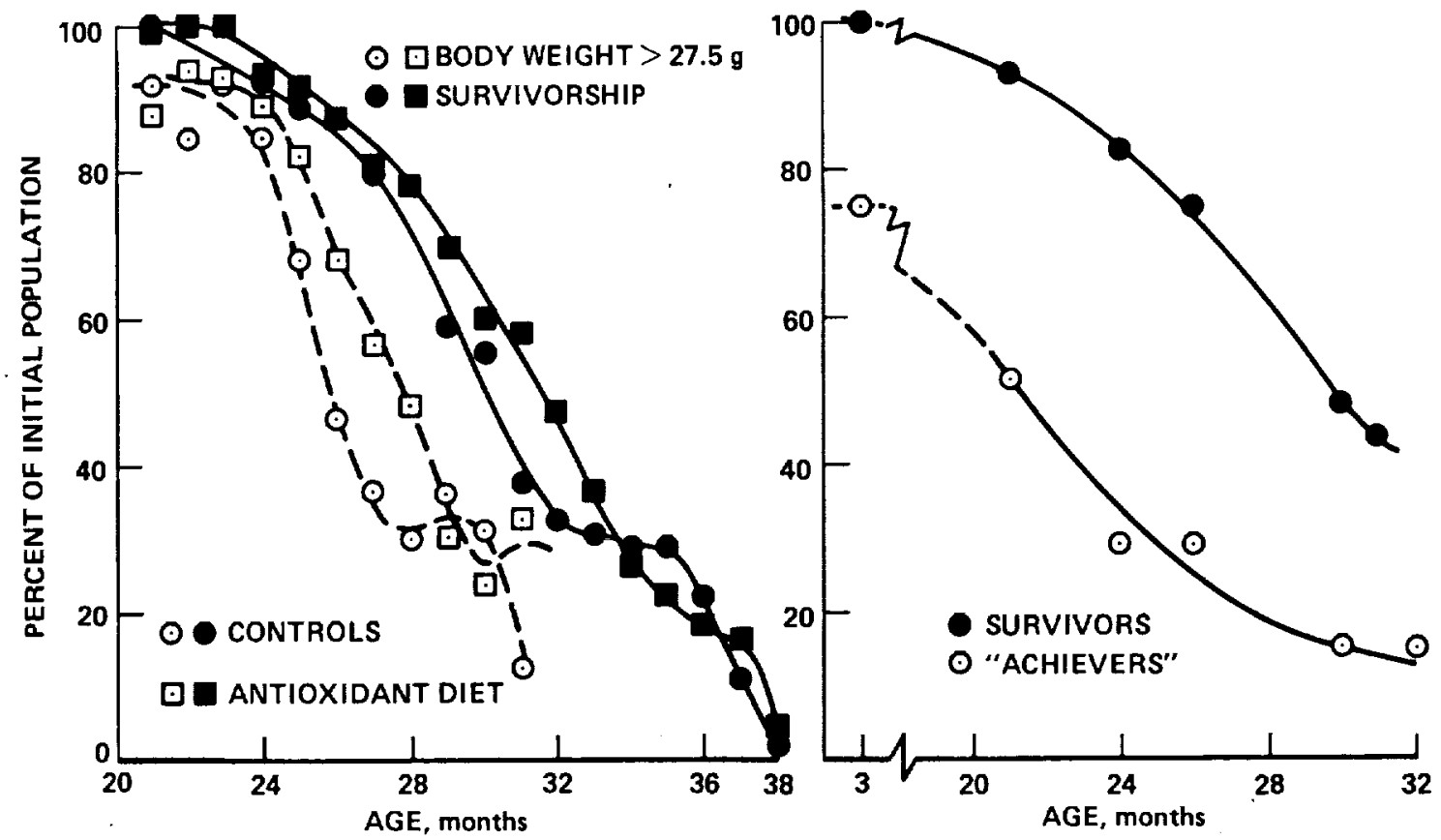

Figure 28. Population vitality curve in mice as predictor of the population's survivorship curve. Body weight (left) and neuromuscular coordination (right) are vitality variables considered here. (See text for more details.) Data from Economos and Miquel (1980) and Miquel and Blasco (1979). 
left, body weight was chosen as the vitality variable, and the data were from the study on which Fig. 25 was based. A rough parallelism was again obtained between vitality and survivorship curves, and the effect of the antioxidant diet on survivorship can be predicted from its effect on the population vitality curve. On the right, the vitality variable was neuromuscular coordination assessed by a special technique (Miquel and Blasco, 1979). When the data were plotted as proposed here, a vitality curve was obtained that again roughly paralleled the survivorship curve.

\section{CONCLUDING REMARKS}

In this chapter we have attempted to show that "some reality lies concealed in biological variation" (Oldham, 1968). This "reality" has its principles, laws, mechanisms, and rules, only a few of which we have sketched. A related idea we pursued was that important information may be lost in the process of ignoring frequency distributions of physiological variables (as is customary in experimental physiology and gerontology). We suggested that it may be advantageous to expand one's "statistical field of vision" beyond simple averages \pm standard deviations.

Indeed, frequency distribution analysis may make visible some hidden information not evident from a simple qualitative analysis, particularly when the effect of some external factor or condition (e.g., aging, dietary chemicals) is being investigated. This was clearly illustrated by the application of distribution analysis in the study of variation in mouse liver cellular and fine structure (Section 4.1), and may be true of fine structural studies in general.

In living systems, structure and function interact in a dynamic way; they are "inseparable," unlike in technological systems or machines. Changes in fine structure therefore reflect changes in function. If such changes do not exceed a certain physiologic range, a quantitative analysis of structure will provide valuable information on quantitative changes in function that may not be possible or easy to measure directly. Because there is a large inherent variation in fine structure of cells in a given organ of an individual and among individuals, changes in fine structure can be analyzed only by studying frequency distribution curves of various structural characteristics (dimensions). Simple averages \pm S.D. do not in general reveal all information on the effect of a certain factor, because of ten this effect is not uniform; on the contrary, this will be apparent from distribution analysis because the form of the curves will be affected.

We have also attempted to show in this chapter that similar general statistical principles and mechanisms may be operative in biological and technological systems. Despite the common belief that most biological and technological characteristics of interest have a symmetric bell-shaped (normal or Gaussian) distribution, we have shown that more often than not, distributions tend to be asymmetric and often resemble a so-called log-normal distribution. We saw that at least three general mechanisms may be operative, i.e., nonadditivity of influencing factors, competition among individuals for a common resource, and existence of an "optimum" value for a studied characteristic; more such mechanisms could exist. As we stressed, all these mechanisms are purely statistical and thus very general, which is illustrated by the similarity of frequency distribution curves of structural and fine structural characteristics of cells with, 
e.g., the curves for physiological vitality, mortality, body weight, latency of mating of fies, glomerular basement membrane width of hamster kidneys, age of fellows of the Royal Society of London, professorial salaries, and capacitor breakdown voltage, to mention only some of the examples we have discussed.

In conclusion, biological variation should be fully recognized and accepted and the effect of aging thereupon should be studied. Thus, variation may become an investigative tool for the experimental gerontologist: when appropriately studied, it can speed up and thus increase the scope of much of experimental gerontology.

\section{REFERENCES}

Andrew, W., 1962, An electron microscope study of age changes in liver of the mouse, Am J. Anat. 110:118.

Andrew, W., 1968, The fine structural and histochemical changes in aging, in: The Biological Basis of Medicine (E. E. Bittar and N. Bittar, eds.), Academic Press, New York.

Bartlett, M. S., 1970, Age distributions, Biometrics 26:377- 385.

Bazovsky, I., 1961, Reliability Theory and Practice, Prentice-Hall, Englewood Clifs, N.J.

Bompas-Smith, J. H., 1973, Mechanical Survival: The Use of Reliability Data, McGraw-Hill, New York.

Brook, R. H. W., 1972, Reliability Concepts in Engineering Manufacture, Wiley, New York.

Calloway, N. O.. and Dollevoet, P. L., 1977, Selected tabular material on aging, in: Handbook of the Biology of Aging (C. E. Finch and L. Hayflick, eds.), Van Nostrand-Reinhold, Princeton, N.J.

Carter, A. D. S., 1972, Mechanical Reliability, Wiley, New York.

Dawkins, R., 1976, The Selfish Gene, Oxford University Press, New York.

Economos, A. C., 1979a, A non-Gompertzian paradigm for mortality kinetics of metazoan animals and failure kinetics of manufactured products, Age 2:74-76.

Economos, A. C., 1979b, Systems Analysis Study of Physiological Adaptation to Weightlessness and Dependence of Adaptation Capacity upon Biological Age, Technical report for NASA.

Economos, A. C., and Miquel, J., 1977, Stochastic analysis of body weight as a tool in time-condensed studies of the effect of various agents on mortality kinetics of mice, 30th Annual Meeting of the Gerontology Society, San Francisco.

Economos, A. C., and Miquel, J., 1979, Analysis of population mortality kinetics with application to the longevity follow-up of the Navy's "1000-aviators," Aviat. Space Environ. Med. 50:397-401.

Economos, A. C., and Miquel, J., 1980, Usefulness of stochastic analysis of body weight of mice as a tool in experimental aging research, Exp. Aging Res 6:417-430.

Economos, A. C., Miquel, J., Binnard, R., and Kessler, S., 1979a, Quantitative analysis of mating behavior in aging male Drosophila melanogaster, Mech. Ageing Dev. 10:233-240.

Economos, A. C., Miquel, J., and Burns, M. K., 1979b, Morphometrics of mouse liver mitochondria: Effects of aging, alcohol and antioxidants, Age 2:134.

Ganong, W. F., 1977, Survey of departments of physiology, 1977, Physiologist 20:23-25.

Gross, A. J., and Clark, V. A., 1975, Survival Distributions: Reliability Applications in the Biomedical Sciences, Wiley, New York.

Haviland, R. P., 1964, Engineering Reliability and Long Life Design. Van Nostrand, Princeton, N.J.

Herbener, G. H., 1976, A morphometric study of age-dependent changes in mitochondrial populations of mouse liver and heart, J. Gerontol. 31:8-12.

Jardine, A. K. S., 1973, Maintenance, Replacement, and Reliability, Wiley, New York.

Johnson, J. E., Jr., Miquel, J., Binnard, R., and Economos, A. C., 1978, Effects of antioxidants on the liver of aging mice, 8th Annual Meeting of the American Aging Association, San Francisco.

Kapur, K. C., and Lamberson, L. R., 1977, Reliability in Engineering Design, Wiley, New York.

Kubis, J. F., 1966, Preface, in: The Biology of Human Variation (E. M. Weyer, ed.), Ann. N.Y. Acad. Sci. 134:501. 
Kunstyr, I., and Leuenberger, H. G. W., 1975, Gerontological Data of C57BL/6J Mice. I. Sex differences in survival curves, $J$. Gerontol. 30:157-162.

MacDonald, E. J., 1963, The epidemiology of melanoma, Ann. N.Y. Acad. Sci. 100:4-5.

McNelly, N. A., and Dittmer, J. E., 1976, Glomerular basement membrane width and proteinuria in the aging hamster kidney, J. Gerontol. 11:49-55.

Miquel, J., and Blasco, M., 1979, A simple technique for evaluation of vitality loss in aging mice, by testing their muscular coordination and vigor, Exp. Gerontol. 13:389-396.

Miquel, J., Lundgren, P. R., and Binnard, R., 1972a, Negative geotaxis and mating behavior in control and gamma-irradiated Drosophila, Drosophila Inform. Service 48:60.

Miquel, J., Bensch, K. G., Philpott, D. E., and Atlan, H., 1972b, Natural aging and radiation-induced life shortening in Drosophila melanogaster, Mech. Ageing Dev. 1:71-97.

Miquel, J., Lundgren, P. R., and Bensch, K. G., 1975, Effects of oxygen-nitrogen (1:1) at 760 Torr on the life span and fine structure of Drosophila melanogaster. Mech. Ageing Dev. 4:41-57.

Miquel J., Lundgren, P. R., Bensch, K. G., and Atlan, H., 1976, Effects of temperature on the life span, vitality and fine structure of Drosophila melanogaster, Mech. Ageing Dev. 5:347-370.

Morowitz, H. J., 1968, Energy Flow in Biology. Academic Press, New York.

Murphy, D. P., 1954, Maternal age and malformation, Ann. N.Y. Acad. Sci. 57:503-506.

Oldham, P. D., 1968, Measurement in Medicine: The Interpretation of Numerical Data, Lippincott, Philadelphia.

Papageorgiou, J. C., 1976, Competition in nature and the lognormal model, Kybernetes 5:31-34.

Papaikonomou, E. (Economos, A. C.), 1974, Biocybernetics, Biosystems Analysis, and the Pituitary Adrenal System, Nooy's Drukkerij, Purmerend, The Netherlands.

Papoulis, A., 1965, Probability, Random Variables, and Stochastic Processes, McGraw-Hill, New York.

Pieri, C., Nagy, I. Z., Mazzufferi, G., and Giuli, C., 1975, The aging of rat liver as revealed by electron microscopic morphometry. I. Basic parameters, Exp. Gerontol. 10:291-304.

Rockstein, M., and Lieberman, H. M., 1959, A life table for the common housefly, Musca domestica, Gerontology 3:23-36.

Schmucker, D. L., and Jones, A. L., 1975, Hepatic fine structure in young and aging rats treated with oxandrolone: A morphometric study, J. Lipid Res. 16:143-150.

Schmucker, D. L., Jones, A. L., and Mills, E. S., 1974, Morphometric analysis of the ultrastructural changes in the liver of aging rats, J. Gerontol. 29:506-513.

Shock, N. W., 1960, Some of the facts of aging, in: Aging: Some Social and Biological Aspects (N. W. Shock, ed.), American Association for the Advancement of Science, Washington, D.C.

Shooman, M. L., 1968, Probabilistic Reliability: An Engineering Approach. McGraw-Hill, New York.

Sohal, R. S., and Bridges, R. G., 1977, Effects of experimental alterations in phospholipid composition on the size and number of mitochondria in the flight muscles of the housefly, Musca domestica, J. Cell Sci. 27:273-287.

Tate, E. L., and Herbener, G. H., 1976, A morphometric study of the density of mitochondrial cristae in heart and liver of aging mice, J. Gerontol. 31:129-134.

Tauchi, H., and Sato, T., 1962, Some micromeasuring studies of the hepatic cells in senility, J. Geronrol. 17:254-259.

Tauchi, H., and Sato, T., 1968, Age changes in size and number of mitochondria of human hepatic cells, J. Gerontol. 23:454-461.

von Alven, W. H. (ed.), 1964, Reliability Engineering, Prentice-Hall, Englewood Cliffs, N.J.

Wilson, P. D., and Franks, L. M., 1975, The effect of age on mitochondrial ultrastructure, Gerontology 21:81-94.

Yeager, V. L., Chiemchanya, S., and Chaiseri, P., 1975, Changes in size of lacunae during life of osteocytes in osteons of compact bone, J. Gerontol. 30:9-14. 